\title{
an
}

Casa abierta al tiempo Universidad Autónoma Metropolitana

\author{
Unidad Iztapalapa \\ División de Ciencias Biológicas y de la Salud \\ Posgrado en Biología Experimental
}

\section{Asociación genética de polimorfismos en el gen $A P O B$ (rs5247904) y citocinas proinflamatorias en hipercolesterolemia familiar}

\author{
TES IS \\ QUE PARA OBTENER EL GRADO DE: \\ MAESTRA EN BIOLOGÍA EXPERIMENTAL \\ PRESENTA: \\ Q.F.B. Maetzin Becerra Sánchez \\ Co-directores: \\ Dr. Alfredo Bobadilla Aguirre \\ Dra. Julia Pérez Ramos \\ Asesor: \\ Dr. José Luis Eduardo Flores Sáenz.
}

México, D.F.

Diciembre 2013 


\section{Comité Tutoral}



Dr. Alfredo Bobadilla Aguirre Jefe del Departamento de Cardiología instituto Nacional de Pediatría bobaalf@yahoo.com.mx

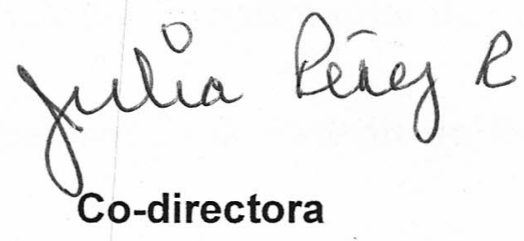

Dra. Julia Pérez Ramos

Laboratorio de Biología Experimental

Universidad Autónoma Metropolitana-Xochimilco jperez@correo.xoc.uam.mx

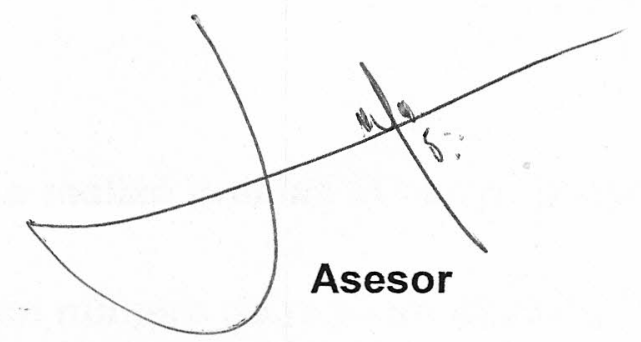

Dr. José Luis Eduardo Flores Sáenz

Coordinador de Servicios Integrados para el Bienestar Universidad Autónoma Metropolitana-Iztapalalpa joseluis_7508@terra.com.mx 
Este trabajo fue realizado en el Departamento de Cardiología del Instituto Nacional de Pediatría, en el Laboratorio de Biología Experimental de la Universidad Autónoma Metropolitana-Xochimilco y en el Laboratorio de Complejo Principal de Histocompatibilidad (HLA) del Instituto Nacional de Enfermedades Respiratorias Ismael Cosío Villegas.

El Programa de Maestría en Biología Experimental de la Universidad Autónoma Metropolitana (UAM-I: 308-1) pertenece al Padrón de Posgrados de Excelencia del CONACyT PIFOP-CONACYT-SEP y cuenta con apoyo del mismo Consejo, con el convenio 309-0, con la clave C/PFPN-2002-35-32.

El presente trabajo se realizó gracias al apoyo proporcionado por el CONACYT a través de la beca con número de registro 420029. 
Los miembros del jurado designado por la División de Ciencias Biológicas y de la Salud, Universidad Autónoma Metropolitana Iztapalapa, abajo firmantes, aprobaron la tesis titulada "Asociación genética de polimorfismos en el gen $A P O B$ (rs5247904) y citocinas proinflamatorias en hipercolesterolemia familiar"

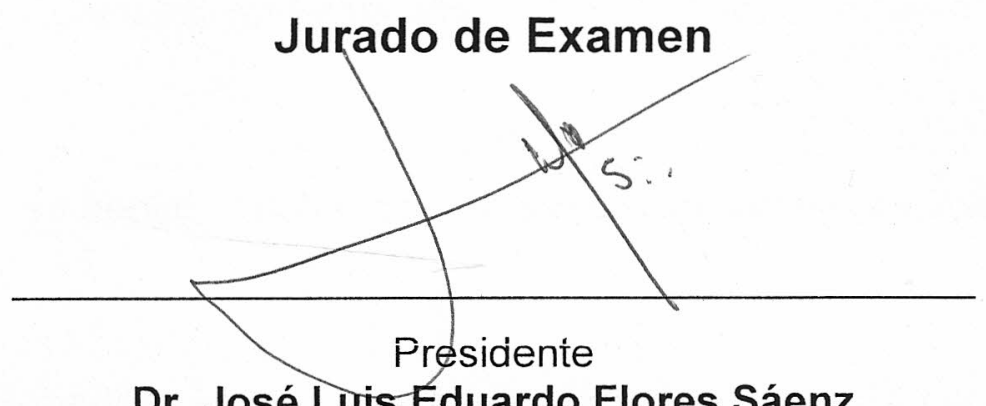

Coordinador de Servicios Integrados para el Bienestar Universidad Autónoma Metropolitana-Iztapalapa

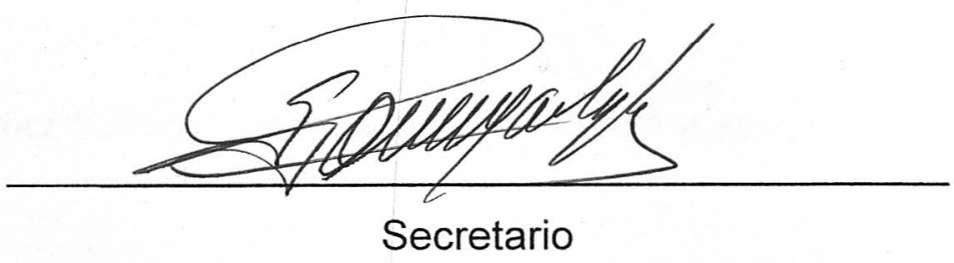

Dr. Humberto González Márquez

Departamento de Giencias de la Salud

Universidad Autónoma Metropolitana



Dr. Edmundo Bonilla González

Jefe del Departamento de Ciencias de la Salud Universidad Autónoma Metropolitana-Iztapalapa

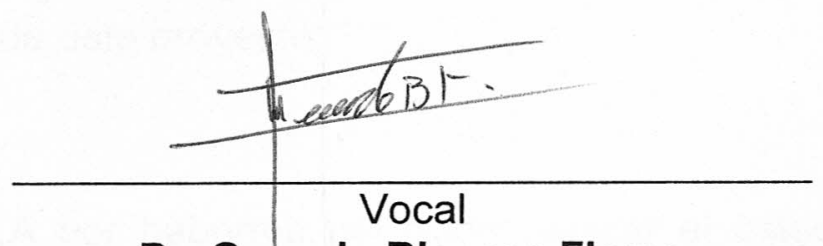

Dr. Gerardo Blancas Flores

Departamento de Ciencias de la Salud

Universidad Autónoma Metropolitana-Iztapalapa 


\section{Agradecimientos}

A la Universidad Autónoma Metropolitana y al Posgrado en Biología Experimental por la oportunidad de continuar mi formación.

Al CONACyT por su apoyo y motivación para la formación de nuevos investigadores.

Al Dr. Alfredo Bobadilla Aguirre por iniciar conmigo este trabajo, por su apoyo, enseñanzas y ejemplo no hubiera sido posible este proyecto.

A la Dra. Julia Pérez Ramos por su ayuda, confianza y apoyo.

Al Dr. José Luis Eduardo Flores Sáenz por su ayuda, consejos, confianza y sobre todo por su ejemplo de ser mejor persona cada día y siempre alentarme.

Al Instituto Nacional de Pediatría por permitir la realización de mi trabajo.

Al laboratorio de Biología Experimental de la UAM-X por haberme permitido realizar el estudio molecular de este proyecto.

Al laboratorio de HLA por haberme permitido realizar el estudio genético de este proyecto. 


\section{Dedicatorias}

A Israel mi esposo, por ser la mejor razón de mi vida para emprender cosas nuevas, de amar, crecer juntos y por estar siempre incondicionalmente conmigo.

A Guadalupe mi mamá, por siempre estar conmigo, creer en mí, aceptarme en cualquier condición y ser mi mejor amiga.

A Juan mi papá, por ser mi amigo y guiarme en la vida.

A la Universidad Autónoma Metropolitana, mí casa de estudio, mi refugio, por ser un lugar que brinda las mejores opciones y siempre tiene las puertas abiertas para sus alumnos. 


\section{Tabla de contenido}

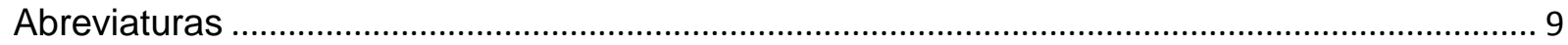



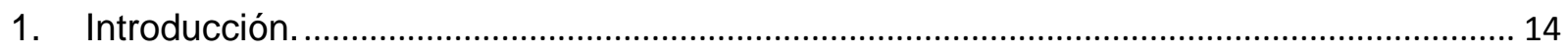

2. Marco teórico

2.1 Hipercolesterolemia .................................................................................... 17



2.1.2 Características clínicas y bioquímicas de la HF ......................................... 19

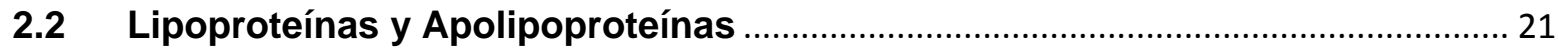

2.2.1 Metabolismo de apoB100 …………………….......................................... 22

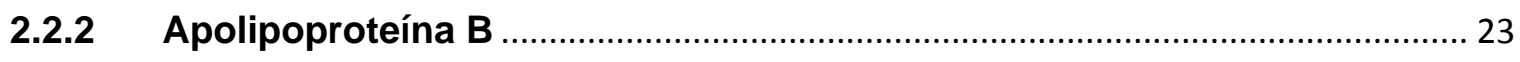

2.3 Mecanismo molecular del defecto familiar de unión de la apolipoproteína B (DFB) 25

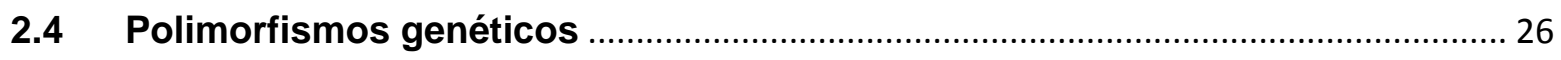

2.5 Hipercolesterolemia y riesgo de enfermedad cardiovascular.............................. 29

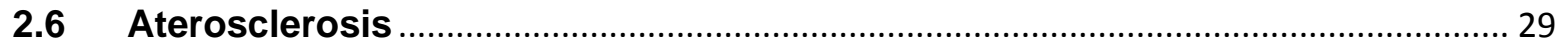

2.6.1 Inflamación y desarrollo de aterosclerosis ................................................. 31

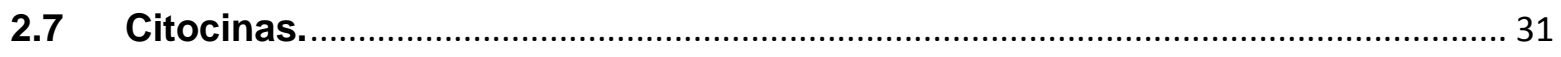

2.7.1 Sistema de citocinas en el desarrollo de la aterosclerosis. ........................ 32

2.7.2 Citocinas implicadas con la aterosclerosis .................................................. 33

2.7.3 Desarrollo de la placa aterosclerótica en la hipercolesterolemia................ 35

2.7.4 Inflamación y trombosis .................................................................................... 36

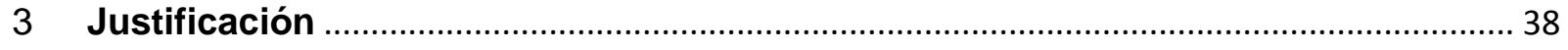

4 Objetivos

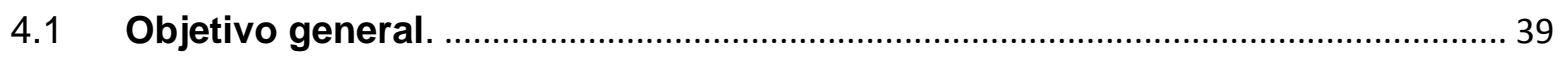

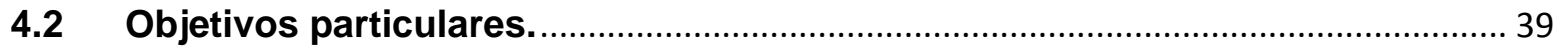

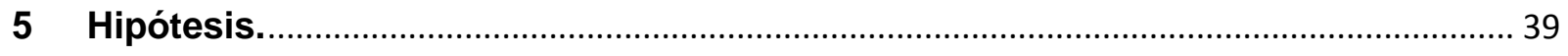

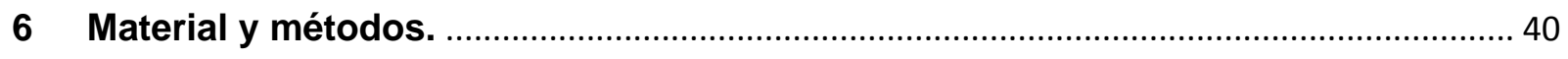

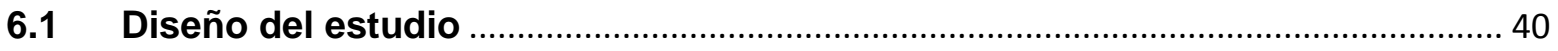




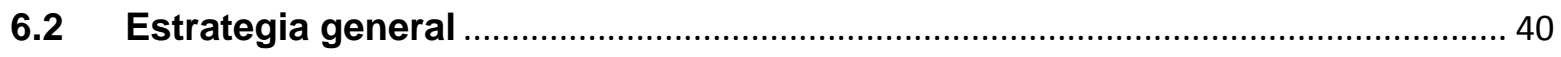

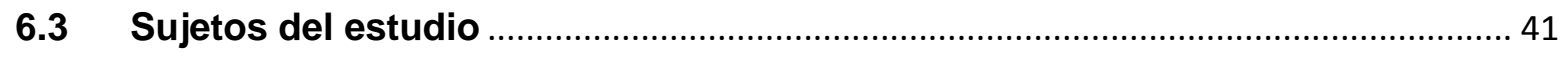

6.3.1 Criterios de Inclusión ................................................................................... 42

6.3.2 Criterios de Exclusión ..................................................................................... 42

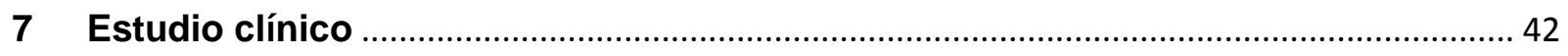

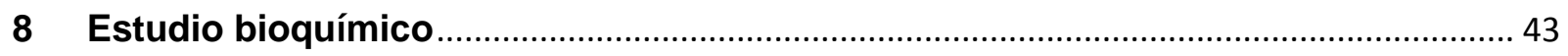

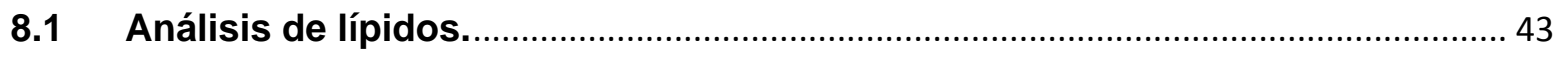

9 Estudio molecular ................................................................................................ 43

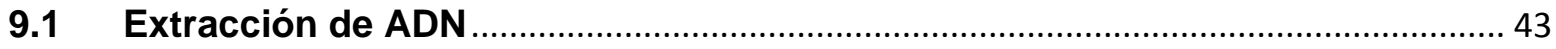

9.2 Identificación de polimorfismos empleando PCR en tiempo real......................... 44

9.3 Procedimiento para realizar la PCR

9.4 Interpretación de graficas de resultado de PCR en tiempo real........................... 47



10.1 Herencia genética representada por medio de árboles genealógicos ................ 51

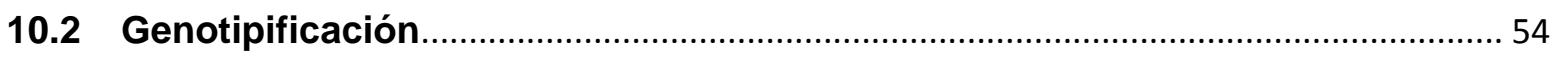

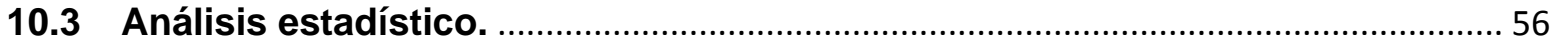

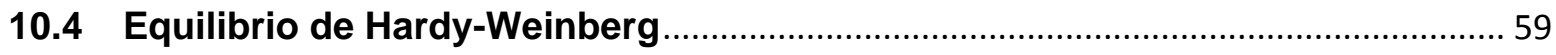

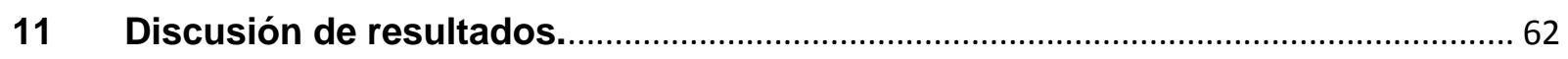



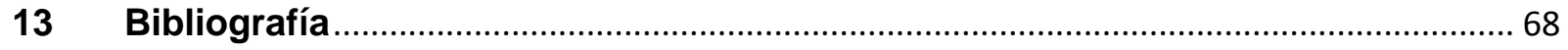

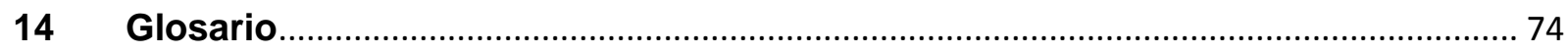

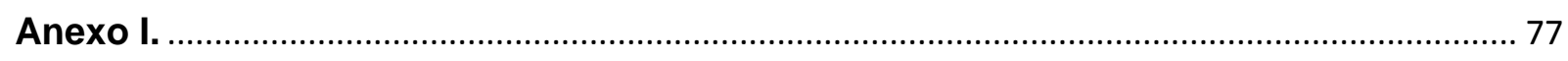

I.1. Técnica para la extracción y cuantificación de ADN. …………………………......... 77

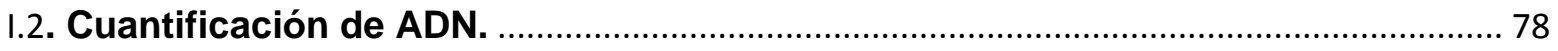

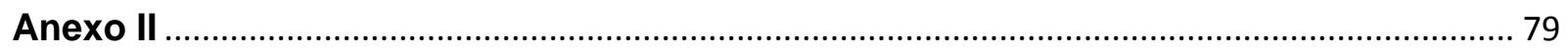

II.1 Reacción en cadena de la polimerasa (PCR) . ......................................................... 79

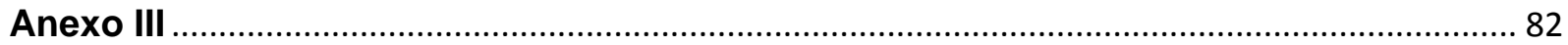


Abreviaturas

\begin{tabular}{|c|c|c|c|}
\hline ADN & Ácido desoxirribonucleico & SNP & $\begin{array}{l}\text { Polimorfismo de un solo } \\
\text { nucleótido }\end{array}$ \\
\hline APOB & Apolipoproteína B & TDT & $\begin{array}{l}\text { test desequilibrio de } \\
\text { transmisión }\end{array}$ \\
\hline CCL & Ligando de quimiocina & TNF & $\begin{array}{l}\text { Factor de necrosis } \\
\text { tumoral }\end{array}$ \\
\hline CSF & $\begin{array}{l}\text { Factor estimulador de } \\
\text { colonias }\end{array}$ & VCAM-1 & $\begin{array}{l}\text { molécula de adhesión } \\
\text { celular vascular }\end{array}$ \\
\hline DFB & $\begin{array}{l}\text { Defecto familiar de unión } \\
\text { de la } \\
\text { apolipoproteína B }\end{array}$ & VLDL & $\begin{array}{l}\text { Lipoproteínas de muy } \\
\text { baja densidad }\end{array}$ \\
\hline ECV & Evento cerebro vascular & & \\
\hline FBAT & $\begin{array}{l}\text { Test basado en asociación } \\
\text { de familias }\end{array}$ & & \\
\hline HAD & $\begin{array}{l}\text { Hipercolesterolemia } \\
\text { autosómica dominante }\end{array}$ & & \\
\hline HDL & $\begin{array}{l}\text { Lipoproteína de alta } \\
\text { densidad }\end{array}$ & & \\
\hline HF & $\begin{array}{l}\text { Hipercolesterolemia } \\
\text { familiar }\end{array}$ & & \\
\hline IAM & Infarto agudo de miocardio & & \\
\hline ICAM & $\begin{array}{l}\text { Moléculas de adhesión } \\
\text { celular }\end{array}$ & & \\
\hline IL-6 & Interleucina-6 & & \\
\hline IMC & Índice de masa corporal & & \\
\hline LDL & $\begin{array}{l}\text { Lipoproteína de baja } \\
\text { densidad }\end{array}$ & & \\
\hline LDLR & $\begin{array}{l}\text { Receptor para lipoproteína } \\
\text { de baja densidad }\end{array}$ & & \\
\hline MAF & Frecuencia alelo menor & & \\
\hline PCR & $\begin{array}{l}\text { Reacción en cadena de la } \\
\text { polimerasa }\end{array}$ & & \\
\hline PCR-TR & $\begin{array}{l}\text { Reacción en cadena de la } \\
\text { polimerasa en tiempo real }\end{array}$ & & \\
\hline PECAM & $\begin{array}{l}\text { Molécula de adhesión } \\
\text { celular endotelial } \\
\text { plaquetaria }\end{array}$ & & \\
\hline
\end{tabular}




\section{Resumen}

La aterosclerosis ocupa uno de los primeros lugares de morbilidad y mortalidad a nivel mundial incluyendo a México, y la hipercolesterolemia es la causa principal para desarrollar esta enfermedad de manera prematura. La hipercolesterolemia familiar (HF) es la forma más grave de hipercolesterolemia, fue la primera enfermedad genética caracterizada clínica y molecularmente del metabolismo de los lípidos.

En la HF se han identificado alteraciones en los genes codificantes del receptor de lipoproteínas de baja densidad (LDLR) y de su ligando, la apolipoproteína B-100 (apoB-100) estas se asocian con el fenotipo hipercolesterolémico y con variantes de los genes de la proteína convertasa subtilisina / kexina tipo 9 (PCSK9).

Se estudiaron 11 pacientes y 33 familiares que asisten al Instituto Nacional de Pediatría con diagnóstico de hipercolesterolemia familiar, y se contó con un grupo control de 48 individuos no relacionados sin evidencia de hipercolesterolemia.

Se determinó la frecuencia alélica y genética de los polimorfismos en el gen de la APOB (rs5247904) y citocinas proinflamatorias CCL1 rs2282691, IL6 rs1818879, TNF rs1800629, TNF rs361525, TNF rs1800750 y CSF2 rs25882 y su asociación genética en el desarrollo de hipercolesterolemia y aterosclerosis. En los tres grupos (pacientes, familiares y grupo control) se cuantificó colesterol total y se compararon los resultados entre los casos sus familias y el grupo control. 
Los resultados obtenidos de los polimorfismos propuestos para el gen $A P O B$ (rs5247904), indican que el genotipo CC no se encuentra asociado con el desarrollo de hipercolesterolemia familiar en nuestra población ya que la frecuencia del alelo menor (MAF) fue del $0 \%$. En el caso de los polimorfismos para las citocinas proinflamatorias los genotipos encontrados fueron: IL-6 AA, TNF GG, CCL1 TT y CSF2 TT, los que tampoco indican algún riesgo ya que presentan una MAF menor del $1 \%$.

Para evitar el desarrollo precoz de aterosclerosis en niños, es necesaria una detección temprana, tratamiento oportuno y a largo plazo de la hipercolesterolemia para prevenir el alto riesgo de enfermedad cardiovascular, principalmente en niños y jóvenes para aumentar la esperanza y su calidad de vida. 


\begin{abstract}
Atherosclerosis is one of the diseases that occupy the first mortality and morbidity places around the world, including Mexico, and hypercholesterolemia is the main cause for the premature development of this disease. Familial hypercholesterolemia $(\mathrm{FH})$ is the most serious form of hypercholesterolemia. It was the first clinically and molecularly characterized genetic disease from lipid metabolism.
\end{abstract}

Alterations in the coding genes from the low density lipoprotein receptor (LDLR) and its ligand, the B-100 apolipoprotein (apoB-100) associated to hypercholesterolemic phenotype and in protein convertase subtisilin/kexin type 9 (PCSK9) have been identified.

Eleven patients and 33 relatives from the Instituto Nacional de Pediatría with a familial hypercholesterolemia diagnostic were studied, and a control group of 48 unrelated individuals without a diagnostic of hypercholesterolemia was available.

Polymorphisms' allelic and genetic frequencies in the APOB (rs5247904) and proinflammatory cytokines CCL1 rs2282691, IL6 rs1818879, TNF rs18006229, TNF rs361525, TNF rs1800750, and CSF2 rs25882 and its genetic association in hypercholesterolemia and artherosclerosis were determined. In all three groups (patients, relatives and control group) total cholesterol was quantified, and results were compared.

The obtained results of the proposed polymorphisms for the APOB (rs5247904) gene indicate that phenotype CC is not associated to familial hypercholesterolemia 
development in our population since minor allele frequency (MAF) was $0 \%$. In the case of polymorphisms for proinflammatory cytokines the genotypes found were: IL-6 AA, TNF GG, CCL1 TT and CSF2 TT, neither of which show any risk since they present a MAF of less than $1 \%$.

To prevent the premature development of atherosclerosis in children, an early hypercholesterolemia detection and opportune long-term treatment are necessary to prevent a high risk of cardiovascular disease, principally in kids and teens, to increase life expectation and quality. 


\section{Introducción.}

La enfermedad aterosclerótica ocupa uno de los primeros lugares entre las causas de morbilidad y mortalidad en México y a nivel mundial y la hipercolesterolemia es la causa principal asociada con riesgo alto de presentar enfermedad aterosclerótica prematura. (García-Moll, et al. 2001)

La HF, es un trastorno hereditario que se caracteriza por el incremento en las concentraciones de colesterol debidas a defectos en el transporte causados por alteraciones en los genes codificantes ya sea en los receptores encargados de internalizar el colesterol a la célula o en las lipoproteínas transportadoras de colesterol. Se han identificado alteraciones en los genes codificantes del receptor de lipoproteínas de baja densidad (LDLR) y de su ligando, la apolipoproteína B-100 (apoB-100) asociadas con el fenotipo hipercolesterolémico y en genes de la proteína convertasa subtilisina / kexina tipo 9 (PCSK9). (Kuan-Rau, et al. 2012)

Estas variaciones genéticas modifican el transporte y metabolismo del colesterol provocando su acumulación en las arterias comenzando el desarrollo de aterosclerosis en etapas tempranas de la vida, y por lo tanto un tratamiento temprano y oportuno pueden prevenir complicaciones en la vida adulta.

La hipercolesterolemia se asocia con disfunción endotelial, una manifestación temprana de la aterosclerosis subclínica, enfermedad y factor de predicción de riesgo de enfermedad cardiaca coronaria en adultos. La disfunción endotelial es evidente en los niños y adultos con hipercolesterolemia familiar. (Engler, et al. 2003). 
En la aterosclerosis, como en otras enfermedades que implican una respuesta inflamatoria, las citocinas provocan el incremento de las concentraciones sanguíneas de reactantes de fase aguda (marcadores de inflamación activa) como el fibrinógeno, la proteína $C$ reactiva $(P C R)$, la proteína sérica $A$-amiloide, el ácido siálico y la ceruloplasmina, y disminuirán las de albúmina. (Domínguez, et al. 2003)

Las citocinas al producirse tras una lesión pueden inducir una respuesta inflamatoria por parte de las células endoteliales, es decir, la inflamación sistémica tiene efectos sobre la vasculatura. Esta respuesta se puede ser causada y se incrementa por factores de riesgo como la hipercolesterolemia. El endotelio estimulado por las citocinas expresa en su superficie glicoproteínas de adhesión, facilitando el reclutamiento de células inmunes de la sangre hacia los tejidos. (Domínguez, et al. 2003)

Se han descrito polimorfismos asociados con hipercolesterolemia familiar, en el exón 26 de la Apolipoproteína B-100 (APOB) que afecta la unión con el receptor para lipoproteínas de baja densidad (LDL), que transportan el colesterol. Además, la liberación de citocinas es un factor decisivo en el desarrollo de aterosclerosis, las alteraciones inflamatorias pueden contribuir con su desarrollo ya que aumentan la disfunción endotelial. Los polimorfismos presentes en citocinas proinflamatorias como Factor de necrosis tumoral (TNF), Interleucina-6 (IL6), Factor estimulador de colonias (CSF) y Ligando de quimiocina (CCL1) pueden causar inflamación crónica que llega a destruir el tejido. (Domínguez, et al. 2003) 
Aunque los marcadores genéticos no se han introducido como herramienta diagnóstica de rutina en el laboratorio clínico, en algunos países se están utilizando para la estimación de gradientes fenotípicos de riesgo individual y a nivel de poblaciones, con la esperanza de intervenir oportunamente en el estilo de vida de las poblaciones de riesgo y alcanzar estrategias terapéuticas adecuadas para cada genotipo.

El objetivo del presente trabajo fue la identificación de polimorfismos del gen $A P O B$ (rs5742904) y de las citocinas proinflamatorias que podrían estar asociadas con el desarrollo de hipercolesterolemia y aterosclerosis. 


\section{Marco teórico}

\subsection{Hipercolesterolemia}

La hipercolesterolemia es un trastorno en el que se presentan niveles elevados de colesterol-LDL en sangre. No puede considerarse como patología sino como un desajuste metabólico que puede ser secundario a muchas enfermedades y que puede contribuir con muchas formas de enfermedad, especialmente cardiovascular. En la hipercolesterolemia por regla general intervienen factores genéticos y ambientales, y la concentración plasmática de colesterol de cada individuo es el resultado de la interacción entre genes y ambiente. En algunos tipos de hipercolesterolemias el factor genético es más importante que los factores ambientales. Desafortunadamente en la actualidad no conocemos la totalidad de los factores ambientales ni tampoco genéticos que intervienen en la homeostasis del colesterol. En algunas familias se han identificado algunas causas genéticas específicas, sin embargo, los genes que están implicados en la hipercolesterolemia no se conocen con precisión y en otros casos como es la HF los defectos responsables, que se sabe que están localizados en un solo gen, son múltiples y variados. (Goldstein, et al. 2001)

Hay una alta frecuencia de hipercolesterolemia en niños y adolescentes que vienen de familias en las cuales existe una alta incidencia de enfermedad cardiovascular en familiares adultos. Así mismo, se ha reportado una elevación en el total de colesterol LDL existente en niños y sus padres, debido a que comparten factores ambientales y genéticos. (Juárez, et al. 2006). 


\subsubsection{Hipercolesterolemia Familiar}

La HF es un trastorno en el metabolismo de las LDL que se hereda de forma autosómica dominante, se caracteriza por niveles altos de LDL-colesterol en plasma, y los resultados son enfermedad cardíaca coronaria prematura. En el heterocigoto, la HF tiene una prevalencia en la población general de 1 en 500 y en el homocigoto de 1 en 1000 por lo que es la forma monogénica más común de hipercolesterolemia (Riba, 2008). La mayoría de los casos de HF son causados por transmisión hereditaria de polimorfismos en el receptor del gen LDL (LDLR). Sin embargo, polimorfismos en otros genes pueden dar lugar a un fenotipo similar de la hipercolesterolemia autosómica dominante (HAD). Por ejemplo, el defecto familiar de unión de la apolipoproteína $B$ (DFB) es debido a polimorfismos en el gen $A P O B$, que codifica para la proteína de unión para el LDLR (Robles-Osorio, 2003). En DFB, polimorfismos tales como Arg3527Gln causan disminución de la unión de la apob100 con su receptor para LDL lo cual conduce a la disminución del aclaramiento de LDL circulante. La DFB se ha establecido como una causa importante de enfermedad cardiovascular aterosclerótica, si bien se manifiesta con un fenotipo menos grave en comparación con el clásico heterocigotos LDLR defectuoso HF. Existe otra forma de HAD rara en la que ocurren polimorfismos en el gen de la proteína convertasa subtilisina/kexina tipo 9 (PCSK9) que causa disminución del aclaramiento de LDL en plasma. (Liyanage et al, 2011)

En 1986, se descubrió el receptor de LDL (LDLR) como causa de hipercolesterolemia autosómica dominante (HAD). Durante años, HAD fue 
considerada como una enfermedad monogénica. Sin embargo, se realizó la búsqueda de otros genes lo que llevo al descubrimiento en 1987 del gen de la apolipoproteína B (ApoB) y en el 2003 del gen de la proteína convertasa subtilina/Kexin 9 (PCSK9), como genes candidatos en la HAD. Estos descubrimientos, fomentaron la idea de una naturaleza poligénica de la HF. (Akl C Fahed, et al. 2011)

En 1938, Müller (citado en Goldstein, 2001) describió, por primera vez, a la enfermedad HAD como un error hereditario del metabolismo que conduce a la presencia de xantomas tendinosos, elevaciones del colesterol plasmático e infarto agudo de miocardio en pacientes jóvenes. Más tarde, Kachadurian (citado por Goldstein, 2001) definió las características clínicas y genéticas de la enfermedad y diferenció los heterocigotos de los homocigotos en familias libanesas afectadas. Goldstein, et al. (2001) caracterizaron al receptor de las LDL y su relación con HAD. Finalmente, en 1983, se clonó el ADN del gen. La frecuencia de heterocigotos se estima en 1/500 en la mayoría de las poblaciones (europeas, norteamericanas y japonesa), y la frecuencia de homocigotos es de 1/1.000.000. (García-Álvarez, 2003)

\subsubsection{Características clínicas y bioquímicas de la HF}

Las manifestaciones clínicas de los pacientes con HF es la presencia de xantomas tendinosos, característicamente observados en los tendones extensores de las manos y los tendones calcáneos, arco corneal (figura 1), los xantomas palpebrales también pueden observarse, pero son características menos específicas de HF. Alrededor de la mitad de los hombres y un tercio de las mujeres con HF han tenido la 
experiencia de un evento coronario a la edad de 60 años, y en niños con HF no tratada por exposición acumulada de las LDL desarrollan aterosclerosis prematura. (Damon A Bell, 2012)

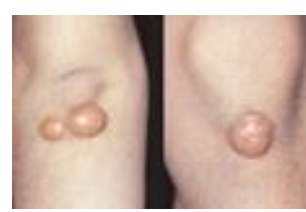

Xantomas



Arco corneal

Figura 1. Manifestaciones clínicas en HF.

La concentración de colesterol total está muy elevada en los pacientes homocigotos, por arriba de $500 \mathrm{mg} / \mathrm{dl}$, con medias en torno a $700 \mathrm{mg} / \mathrm{dl}$. La elevación del colesterol total se debe exclusivamente al aumento de los niveles de LDL. Esta concentración se modifica muy poco a lo largo de la vida del sujeto y sufre pocas variaciones debido a factores ambientales (Goldstein, et al. 2001). Las diferencias principales dependen de la naturaleza de la mutación en caso de los homocigotos, o de las mutaciones, en caso de heterocigotos, observándose una buena correlación entre la actividad residual del receptor y la concentración de LDL.

La HF no tratada acorta la esperanza de vida, entre 20 y 30 años, con respecto a la población general, ya que la mayoría de las personas que sufren esta hiperlipidemia fallecen por aterosclerosis que es su manifestación más importante. En sujetos homocigotos verdaderos o heterocigotos compuestos sin tratamiento hipolipemiante, la aterosclerosis suele aparecer antes de los 30 años. (Goldstein, et al. 2001). Al analizar la mortalidad coronaria de forma prospectiva en un grupo de HF 
heterocigotos seguidos durante casi 10 años se observó que el riesgo de muerte coronaria entre los 20-74 años fue de 3,7 veces superior a lo esperado en los varones y de 4,1 veces en las mujeres. Goldstein et al (2001) fijan una frecuencia de aterosclerosis en pacientes con HF heterocigota del 20, 45 y $75 \%$ a los 40,50 y 60 años respectivamente, para los varones, y del 30, 20 y $45 \%$ para las mujeres a la misma edad.

\subsection{Lipoproteínas y Apolipoproteínas}

Las lipoproteínas son complejos macromoleculares de proteínas transportadoras específicas, denominadas apolipoproteínas, con combinaciones diversas de fosfolípidos, colesterol, ésteres de colesterol y triacilgliceroles. Las apolipoproteínas ("apo" designa la proteína en su forma libre de lípidos) se combinan con los lípidos para formar varias clases de partículas lipoprotéicas, complejos esféricos con lípidos hidrofóbicos en el núcleo y cadenas laterales hidrofílicas de aminoácidos de la proteína en la superficie figura 2. Varias combinaciones de lípidos y proteínas dan lugar a partículas de densidades diferentes, que van desde los quilomicrones hasta las lipoproteínas de alta densidad (HDL). (Voet, 2006) 




Figura 2. Estructura de una lipoproteína. Complejos macromoleculares compuestos por proteínas y lípidos que transportan TG, CHO y Fosfolípidos.

Cada clase de lipoproteína tiene una función específica, determinada por su lugar de síntesis, composición lipídica y contenido en apolipoproteínas. Al menos nueve clases diferentes de apolipoproteínas pueden encontrarse entre las lipoproteínas del plasma humano. Las apolipoproteínas pueden diferenciarse por su tamaño, reacciones con anticuerpos específicos y distribución característica en las clases de lipoproteínas. Estos componentes proteínicos actúan como señales dirigiendo las lipoproteínas a tejidos específicos o como activadores de enzimas que actúan sobre las lipoproteínas. (Voet, 2006)

\subsubsection{Metabolismo de ApoB100}

En el hígado se forman triacilgliceroles a partir de ácidos grasos tomados del plasma o sintetizados por el propio tejido. El colesterol se puede sintetizar también por el hígado o serle suministrado través de los restos de quilomicrones. Estos núcleos lipídicos se ensamblan con ApoB100 y fosfolípidos en las VLDL, y se agregan al 
plasma. Las partículas de VLDL de menor tamaño, más densas, se convierten de forma eficiente en LDL. La única proteína que permanece sobre la superficie de la partícula de LDL, es la ApoB100. La mayoría de la LDL plasmática se capta por el hígado y el resto se suministra a los tejidos periféricos, incluyendo las suprarrenales y las gónadas, que emplean el colesterol como precursor de la síntesis de esteroides. (Harrison., 2001)

\subsubsection{Apolipoproteína B100}

La ApoB es una proteína de características únicas. Es la de mayor masa molecular en el humano (545kDa), está constituida por 4536 aminoácidos. De su gen localizado en el brazo corto del cromosoma 2 (2p23-p24) se derivan dos productos (ApoB100 y ApoB48). El gen de la ApoB100 contiene 29 exones (figura 3), de los cuales 24 se encuentran en el tercio 5'. Los exones 26 (7572 bases) y 29 (1906 bases) son los de mayor tamaño en el humano. (Aguilar et al, 2008)

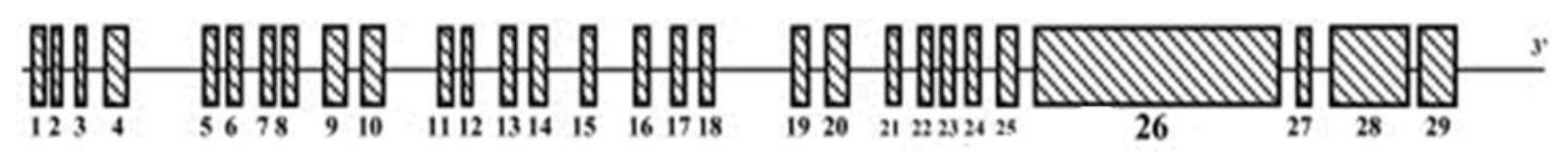

Figura 3. Gen de la APOB, contiene 29 exones.

La ApoB100 es el único componente proteínico de la LDL que reconoce el receptor de LDLR, figura 4. La ApoB100 se sintetiza en el hígado. Constituye el ligando para la eliminación de las LDL por el receptor de LDL. El receptor de LDL es una proteína de la superficie celular que liga las lipoproteínas que contienen ApoB100 y las transporta al interior de la célula. 


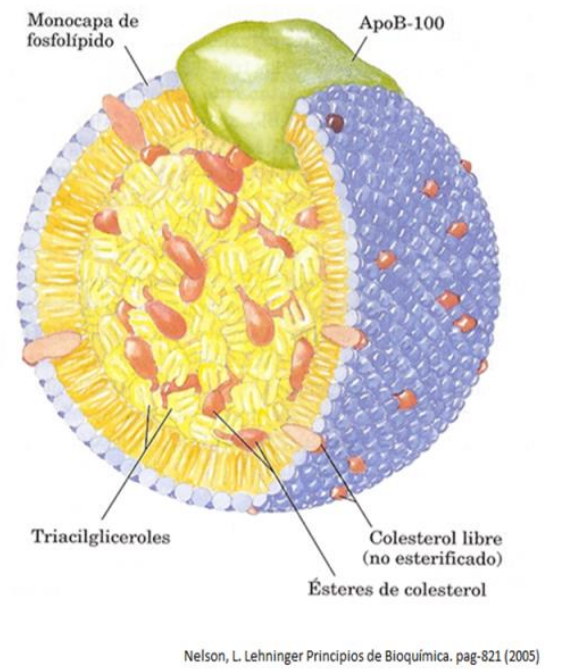

Figura 4. Estructura de la apolipoproteina B100. Es el único componente proteico de la lipoproteína de baja densidad ( $L D L)$ que reconoce el $L D L R$, por medio de la ApoB100.

La mayoría de los polimorfismos en ApoB100, se localizan en una región del exón 26 que codifica el dominio de unión de ApoB100 al receptor de LDL. Estos polimorfismos afectan el transporte de LDL al interior celular, conduciendo al incremento de la concentración de LDL circulante. El defecto más común en el gen ApoB100 es un cambio CGC a CAG en el codón 3500 sustituye la Arginina de la posición 3500 por Glutamina (R3500Q) y se le conoce con el sobrenombre del polimorfismo ApoB 3500 (Arg3500Gln), polimorfismo que disminuye la afinidad de unión de ApoB100 a LDLR, aunque también se han descrito polimorfismos Arg3500Trp y Arg3531Cys. (Arráiz, et al. 2011) 
Los polimorfismos identificados en ApoB100, se localizan en una región del exón 26 que flanquea el codón 3500 del gen. Debido a que esta región codifica para el dominio de unión de ApoB100 al receptor de LDL, las mutaciones afectan el transporte de LDL al interior celular, conduciendo al incremento de la concentración de LDL circulante. (Ejarque, et al. 2004)

Se han descrito cuatro polimorfismos localizados en el gen de la ApoB100 (R3500Q, R3500W, R3531C y R3480P) son los responsables del DFB. El más prevalente de ellas es el polimorfismo R3500Q. (Ejarque, et al 2004)

\subsection{Mecanismo molecular del defecto familiar de unión de la ApoB100.}

Al momento de la descripción del defecto de unión en ApoB100 se atribuyó al cambio del aminoácido anormal con el sitio de unión al receptor. Pero se descubrió que su efecto lo realiza a distancia cambiando la estructura secundaria o conformación de la ApoB100. El 89\% de la ApoB100 engloba la partícula de LDL como un cinturón y el $11 \%$ restante que corresponde al carboxilo terminal se pliega sobre sí mismo cerca del residuo 3500. La región que une al receptor llamado sitio B (3359-3369), queda adyacente sobre el sitio donde se repliega la región carboxilo terminal de la ApoB100. Para que la ApoB100 efectué una conformación correcta de la cola carboxilo terminal, la arginina 3500 debe interactuar con el triptófano 4369 y esta interacción es esencial para la estructura y función correctas (figura 5). Al existir el cambio del nucleótido se origina el cambio del aminoácido de arginana por glutamina alrededor del residuo 3500 esto origina que ya no exista interacción entre arginina y triptófano lo que provoca un cambio cambio en la conformación y posición de la cola 
del carboxilo terminal el cual actúa como un modulador negativo que inhibe la unión con el receptor.(Borén et al, 2001)

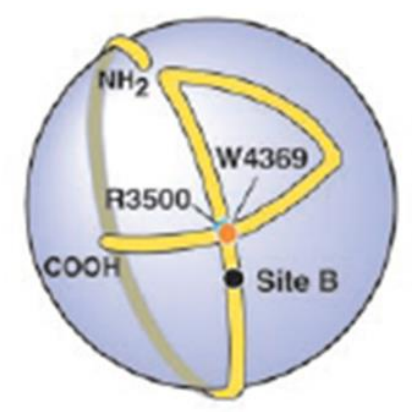

Apo-B100

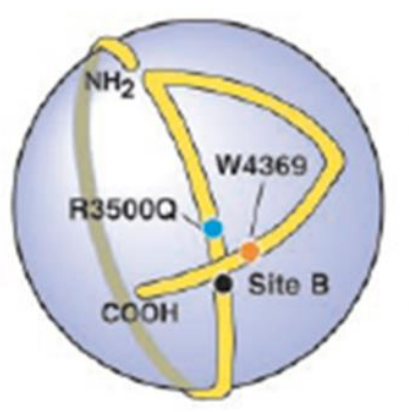

Apo-B100 (FDB)

Receptor

Binding

Figura 5. Modelo de unión al receptor LDL y la ApoB100 en condiciones normales interacción de arginina con triptófano (izquierda) y unión cuando existe cambio de arginina por glutamina (derecha).

\subsection{Polimorfismos genéticos}

Dentro de la semejanza entre los individuos de una misma especie, estimada en un $99,9 \%$ del genoma humano, existen variaciones individuales en la secuencia del ADN, muchas de ellas neutras, es decir, sin efecto alguno sobre la información genética, ya que afectan a secuencias no codificantes ni funcionales del ADN. Este $0,1 \%$ de variaciones en las secuencias de ADN entre individuos es lo que se conoce como polimorfismos genéticos. Los polimorfismos consisten, por tanto, en variaciones en la secuencia del ADN, tengan o no consecuencia biológica selectiva alguna, que se detectan en al menos el 1\% de los individuos de una población. En la práctica, para que un locus sea considerado polimórfico el alelo más común de dicho 
locus debe tener una frecuencia poblacional menor del $99 \%$ y, de acuerdo con la ley de Hardy-Weinberg, al menos un $2 \%$ de la población debe ser heterocigota para ese locus. A los alelos con frecuencias menores de $1 \%$ se le llaman variantes raras 0 mutación. (Checa, 2007)

Desde hace casi un siglo se utilizan los polimorfismos genéticos para estudiar las variaciones entre individuos. Son caracteres estables que se transmiten por herencia mendeliana simple y constituyen una expresión de la diversidad genética entre individuos de la misma especie.

Las variantes genéticas más estudiadas en los seres humanos son los polimorfismos de un solo nucleótido o SNP (del inglés single nucleotide polymorphism, en la jerga científica se pronuncia snip y al plural se le denomina SNPs), las cuales corresponden a sustituciones de un nucleótido por otro en la cadena del ADN. Los SNPs constituyen hasta el $90 \%$ de todas las variaciones genómicas humanas, y aparecen cada 100 a 300 bases en promedio a lo largo del genoma humano. En las bases de datos públicas internacionales se encuentran más de 6 millones de SNPs y es probable que existan más de 10 millones de SNPs. Los polimorfismos se distinguen terminológicamente de las mutaciones por su frecuencia. Las formas de los polimorfismos (llamados "alelos") son más frecuentes que las mutaciones, esto es, en una frecuencia mayor al 1\%. La gran mayoría de los SNPs tienen dos alelos los que están representados por una sustitución de una base por otra. En las poblaciones, este tipo de alelos se clasifican en alelo principal o "silvestre" y alelo raro o mutante, clasificación basada en la frecuencia observada en las poblaciones. 
Debido a que los humanos son diploides, un individuo puede tener uno de tres genotipos: homocigoto para el alelo más frecuente, heterocigoto, u homocigoto para el alelo menos frecuente. (Cordell, et al. 2005)

Aunque la mayoría de los SNP se encuentran en regiones no funcionales del ADN o son sinónimos (se produce un cambio de nucleótido que genera el mismo aminoácido, sin alterar por tanto la cadena de ADN), careciendo de efecto biológico, también los hay que afectan a regiones codificantes o funcionales del genoma, pudiendo modificar el sentido de un codón o alterar la expresión de un gen. Se ha propuesto la hipótesis de que estos últimos polimorfismos son los responsables de gran parte de las diferencias hereditarias entre individuos, pudiendo determinar la respuesta individual a factores ambientales y farmacológicos y la predisposición genética a muchas enfermedades, especialmente complejas. Además de su creciente interés y utilización para los estudios de asociación entre factores genéticos y enfermedad, los SNP también son de gran interés en genética de poblaciones y evolutiva.

Dentro de la epidemiología genética, existen dos abordajes para la búsqueda de los genes y variantes genéticas que participan en los rasgos y enfermedades comunes: a) los estudios de ligamiento, los cuales se basan en el estudio de la herencia de marcadores genéticos y fenotipos dentro de familias con individuos afectados; y b) los estudios de asociación genética basados en la identificación de diferencias significativas en la frecuencia de variantes genéticas entre grupos de estudio, generalmente un grupo de casos (individuos enfermos) y uno de controles (individuos 
sanos), el conocimiento de las variantes en estos grupos lleva a la identificación de factores genéticos asociados con riesgo o protección. (Cordell, et al. 2005)

\subsection{Hipercolesterolemia y desarrollo de aterosclerosis}

\subsection{Aterosclerosis}

La aterosclerosis es un proceso inflamatorio crónico que afecta a las arterias que se caracteriza por el engrosamiento de la capa íntima y media con pérdida de la elasticidad. La lesión básica de la aterosclerosis consiste en una placa focal elevada dentro de la íntima, con un centro lipídico (principalmente colesterol y ésteres de colesterol) y una capa fibrosa que lo cubre. Los ateromas que son una degeneración grasa o engrosamiento de las paredes, se distribuyen de forma dispersa cubriendo, en ocasiones, toda la circunferencia de las arterias, en consecuencia los ateromas son oclusivos, comprometiendo el flujo sanguíneo hacia los órganos distales y provocando una lesión isquémica. (Kumar 2005). La aterosclerosis coronaria suele causar angina de pecho, infarto de miocardio, infarto cerebral y aneurismas aórticos. (Harrison, 2001)

Afecta a arterias de varias localizaciones simultáneamente pero con grado diferente de progresión. Tiende a asentarse en las arterias que irrigan el corazón (coronarias), el cerebro (carótidas, vertebrales y cerebrales) y las extremidades inferiores (iliacas y femorales). Por lo tanto, la presencia de afectación vascular en una localización concreta se asocia con un mayor riesgo de desarrollarla en otros lechos vasculares 
como se muestra en la figura 6. Esta enfermedad puede comenzar en etapas tempranas de la vida, cuando las lipoproteínas de baja densidad se depositan en las paredes de las arterias. La evidencia de la importancia de las LDL proviene de fuentes experimentales, epidemiológicas y genéticas. Las personas con hipercolesterolemia familiar se encuentran en riesgo y representan alrededor del $15 \%$ de las personas que pueden sufrir enfermedad prematura coronaria. (Sveger, 2004)

Los niveles de la LDL están asociados con un aumento del riesgo de enfermedades cardiovasculares y evento cerebro vascular (ECV). Estudios recientes sugieren que un $40 \%$ a $80 \%$ de la variación en los niveles de LDL de la población es atribuible a factores genéticos. Ésta en la población general es probablemente poligénica y por factores ambientales. Formas raras de hipercolesterolemia monogénica han sido identificadas, incluyendo la hipercolesterolemia familiar debida a polimorfismos en el gen del receptor de LDL y el defecto familiar de unión de la apolipoproteína B (DFB) debido a polimorfismos del gen de la $A P O B$. (Shen, 2010)

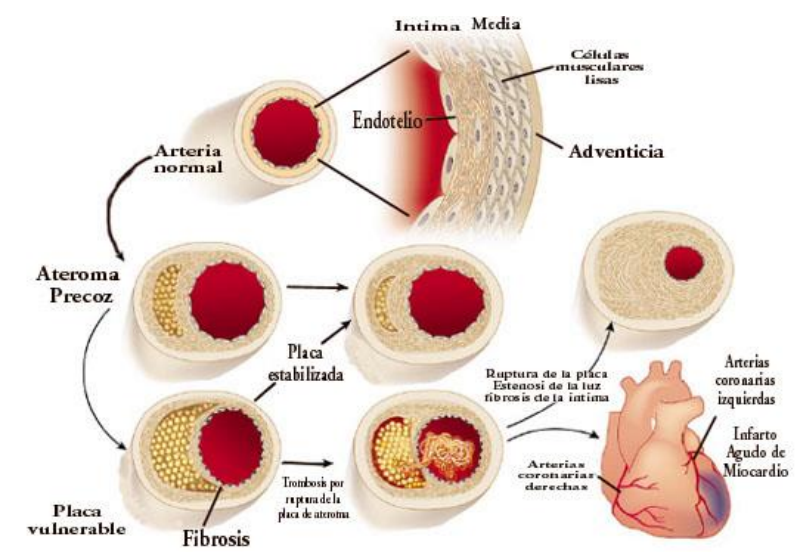

Figura 6. Etapas de desarrollo de la aterosclerosis. Al aumentar los niveles de LDL en la sangre estos interaccionan con componentes del endotelio arterial que internalizan las partículas LDL a la capa íntima sufriendo modificaciones químicas como oxidación 
lo cual estimula una respuesta inflamatoria y producción de diversas citocinas y moléculas de adhesión y migración de macrófagos al interior de la íntima. Estos macrófagos fagocitan las LDL oxidadas y se transforman en células espumosas que secretan más citosinas que estimulan migración de células musculares lisas que forman el casquete firbroadiposo, Finalmente muchas células perecen y se rompen liberando su contenido al lumen vascular provocando trombosis e infarto.

\subsubsection{Inflamación y desarrollo de aterosclerosis}

La aterosclerosis es un proceso complejo que implica varios tipos de células (como las células endoteliales, musculares lisas vasculares, macrófagos y linfocitos) y numerosas familias de citocinas y factores de crecimiento. En la aterosclerosis estas moléculas inducen una respuesta inflamatoria, las citocinas aumentarán las concentraciones sanguíneas de reactantes de fase aguda (marcadores de inflamación activa) como el fibrinógeno, la proteína $\mathrm{C}$ reactiva $(\mathrm{PCR})$, la proteína sérica A-amiloide, el ácido siálico y la ceruloplasmina. (García-Moll, et al. 2001)

La inflamación es una respuesta del huésped a una gran variedad de lesiones tisulares, caracterizada por el movimiento de células y fluidos desde la sangre hacia los tejidos extravasculares en el lugar en el que se ha iniciado el estímulo nocivo, bajo la influencia de factores quimiotácticos producidos localmente. (García-Moll, et al. 2001)

\subsection{Citocinas.}

Entre las moléculas que participan en el proceso inflamatorio, las citocinas son las que parecen orquestar el desarrollo crónico de la aterosclerosis. Éstas pueden llevar a la formación de las placas de ateroma, que provocan complicaciones trombóticas agudas, tales como el infarto agudo de miocardio (IAM). En las placas 
arterioscleróticas se han detectado varias citocinas pro-inflamatorias, entre las que destacan la IL-1, IL-6, así como TNF-a. (García-Moll, et al. 2001)

Las citocinas al producirse tras una lesión tienen efectos sobre la vasculatura, es decir, la inflamación sistémica puede inducir una respuesta inflamatoria por parte de las células endoteliales. Dicha respuesta puede ser causada por factores de riesgo como la hipercolesterolemia. El endotelio estimulado por las citocinas expresa glicoproteínas de adhesión en su superficie, y aumenta la expresión de moléculas de adhesión, facilitando el reclutamiento de células inmunes de la sangre hacia los tejidos. (Domínguez, et al. 2003)

Las células endoteliales activadas también pueden producir citocinas como las IL-1 o IL-6, y mediadores vasoactivos poderosos como el factor activador plaquetario, que potencian las respuestas inmunes e inflamatorias. Las glicoproteínas adhesivas son miembros de la familia de las selectinas (selectina $E$ y selectina P) y de la superfamilia de las inmunoglobulinas (molécula 1 de adhesión de plaquetas a células endoteliales o platelet-endothelial cell adhesion molecule-1 (PECAM-1), moléculas de adhesión intercelular (ICAM) y molécula 1 de adhesión de células vasculares (VCAM-1). (Cordell, et al. 2005)

\subsubsection{Sistema de citocinas en el desarrollo de la aterosclerosis.}

Dentro del sistema que conforman las citocinas que desarrollan aterosclerosis se encuentran principalmente IL-6 que se encuentra en el cromosoma 7, TNF (presenta varios polimorfismos), CCl1, CFS2, todas las cuales al presentar algún polimorfismo producen cambian que alteran la función normal lo que puede originar 
enfermedades o trastornos en el organismo. En la tabla 1 se describen las citocinas que participan en el desarrollo de aterosclerosis. (García-Moll, et al. 2001)

Tabla 1. Citocinas participantes en el desarrollo de aterosclerosis.

\begin{tabular}{|c|c|c|}
\hline Gen & Cromosoma & Localización \\
\hline IL-6 & 7 & Intrón \\
\hline TNF & 6 & Promotor \\
\hline CCL1 & 17 & Intrón \\
\hline CFS2 & 5 & Exón Ile/thr \\
\hline
\end{tabular}

\subsubsection{Citocinas implicadas con la aterosclerosis}

IL-6. Es producida por monocitos y macrófagos, fibroblastos, células endoteliales, linfocitos T y células del estroma de la médula ósea. Junto con la IL-1, la IL-6 es la principal inductora de la síntesis de proteínas de fase aguda, sobre todo de fibrinógeno. Además posee efectos pro-inflamatorios y se ha observado que promueve la diferenciación de linfocitos $B$ hacia células plasmáticas, producción de inmunoglobulinas y facilita la maduración de precursores hematopoyéticos dependientes de la IL-3.

TNF. Los factores de necrosis tumoral (TNF) fueron descritos inicialmente por su capacidad de causar necrosis en algunos tumores, pero con posterioridad, sin embargo, ganaron protagonismo por las numerosas funciones que ejercen sobre la respuesta inmune. Se han descrito dos moléculas estrechamente relacionadas, el TNF-alfa y el TNF-beta, con elevada homología en su secuencia aminoacídica. En 
concreto el TNF alfa es producido por monocitos y macrófagos en respuesta a antígenos bacterianos, tales como el LPS. Esta citocina, es la principal responsable del shock séptico asociado a bacteriemias y que puede ser en muchos casos de extrema gravedad, conduciendo al individuo, en muchos casos, a la muerte.

CSF2. Es producido por monocitos y macrófagos maduros activados y está implicado en el desarrollo de las células progenitoras de los macrófagos.

CCL1. Son quimiocinas que estimulan el movimiento de los leucocitos y regulan su migración desde la sangre a los tejidos. Se producen en leucocitos, células endoteliales, epiteliales y fibroblastos en respuesta a estímulos inflamatorios. La secreción de quimiocinas $\mathrm{CC}$ se induce por la acción de microorganismos y citocinas inflamatorias en especial TNF, IL1 y linfocitos T.

La inflamación aguda se caracteriza por la acumulación de neutrófilos. Si la respuesta inflamatoria queda confinada localmente se producirá una lesión menor, pero si el estímulo inflamatorio es más importante generará una reacción sistémica generalizada denominada «respuesta de fase aguda», que posteriormente disminuye y retorna a la normalidad. Cuando el estímulo inflamatorio es persistente o se repite continuamente se producirá una inflamación crónica, que puede llegar a destruir el tejido y/o producir la pérdida de la funcionalidad del órgano afectado. El infiltrado de células inmunes típico de la inflamación crónica está compuesto por macrófagos, linfocitos y células plasmáticas. La liberación crónica de mediadores de la inflamación producirá lesión tisular, cicatrización y la posible pérdida de la función tisular. 
Cuando estas glicoproteínas se expresan en la superficie de las células endoteliales son reconocidas por integrinas presentes en la superficie de monocitos y linfocitos $\mathrm{T}$. Una vez que estas células se enganchan a la superficie endotelial, los monocitos y los linfocitos T migran hacia el interior de la pared vascular a través de las uniones entre células endoteliales.

Este proceso se ve influido por moléculas reguladoras del crecimiento y sustancias quimioatractivas liberadas tanto por las células endoteliales como por los leucocitos adheridos (p. ej., interleucinas [IL-8], leucotrienos, factor del crecimiento derivado de las plaquetas (PDGF), proteína 1 quimiotáctica de monocitos (MCP-1 o PECAM-1). La MCP-1, además de inducir la liberación de histamina y leucotrienos como la IL-8, atrae a linfocitos CD4+ y CD8+ hacia el lugar de inflamación, y puede estimular la liberación de citocinas inflamatorias como IL-1 y IL-6 de los monocitos.

\subsubsection{Desarrollo de la placa aterosclerótica en la hipercolesterolemia.}

A medida que progresa el proceso inflamatorio, los monocitos llegan al espacio subintimal y a la capa media arterial, donde pasan a considerarse macrófagos. Éstos acumulan lípidos del interior de la pared arterial y liberan nuevos factores de crecimiento y citocinas, que atraerán a nuevos macrófagos y células musculares lisas al lugar de inflamación. Estas moléculas producidas por las células presentes en la placa aterosclerótica inducen y regulan una gran cantidad de funciones celulares, como la proliferación, quimiotaxis, producción de moduladores inmunes y acumulación de varios componentes de la matriz de colágena. Las citocinas aumentan la producción de radicales libres y enzimas en células endoteliales y en 
macrófagos. Ambas contribuyen a la oxidación de las LDL. Las LDL oxidadas son un ligando para un receptor macrofágico, que a su vez también se expresa en mayor cantidad en macrófagos activados por citocinas. Este receptor se une a las LDL oxidadas y las internaliza. La acumulación de LDL oxidadas en el interior de los macrófagos producirá la típica morfología de célula espumosa, característica en las lesiones ateroscleróticas. Estas células podrán presentar antígenos a linfocitos, potenciando la respuesta inmune. Otros linfocitos T secretarán IL-10 para limitar los procesos proinflamatorios. El resultado final dependerá del balance de estas influencias contrapuestas. Finalmente, la inflamación también interviene en el proceso activo de la rotura de la placa aterosclerótica. Algunas citocinas y factores de crecimiento están implicados en la síntesis de colágeno en el casquete fibroso de las placas. (García-Moll, et al. 2001)

\subsubsection{Inflamación y trombosis}

Existe un vínculo claro entre inflamación y trombosis, que se influyen de forma recíproca. Las células endoteliales estimuladas por citocinas (como el TNF) producen sustancias procoagulantes como el factor Von Willebrand, el factor tisular y los inhibidores 1 y 2 del activador del plasminógeno. Las células inflamatorias activadas sintetizan moléculas que modulan la cascada trombótica. Las citocinas proinflamatorias que inician la respuesta inflamatoria son la IL-1, la IL-6 y TNF. Además, cuando las citocinas actúan se producen multitud de mediadores de inflamación, ya sean proteínicos como el fragmento del complemento C5a, o lipídicos como el factor activador plaquetario. Estos mediadores tendrán acciones sinérgicas, 
induciéndose su producción entre ellos, e induciendo la producción de otras citocinas que frenarán o aumentarán las vías de autocontrol. Las citocinas también son responsables de la finalización correcta de la respuesta inflamatoria. (Domínguez, et al. 2003) 


\section{Justificación}

La enfermedad cardiovascular es la causa principal de mortalidad en México y en el mundo y la hipercolesterolemia está asociada con un riesgo alto de enfermedad cardiovascular. La causa principal de aterosclerosis es la hipercolesterolemia que se caracteriza por el incremento en las concentraciones de colesterol de causa multifactorial, pero debidas, principalmente, a defectos en su transporte, causados por variaciones de los genes ya sea en los receptores encargados de internalizarlo a la célula o en las lipoproteínas (apoB-100) transportadoras. Aunque la detección oportuna de niveles altos de colesterol en niños y adolescentes que provienen de familias con antecedentes de hipercolesterolemia y de enfermedades cardiovasculares disminuye los factores de riesgo para desarrollar aterosclerosis, el problema persiste y se desconocen las variantes genéticas que incrementan este riesgo, la detencción de polimorfismos ayudará a identificar las causas profundas del incremento de las concentraciones de colesterol.

Varios polimorfismos de los genes implicados en el metabolismo del colesterol y en citosinas proinflamatorias se han asociado con hipercolesterolemia familiar y aterosclerosis, entre ellos se encuentran los del exón 26 del gen APOB que disminuyen la afinidad con el receptor LDL.

En México hacen falta más estudios para caracterizar la frecuencia alélica de los polimorfismos del exón 26 del gen APOB y citocinas proinflamatorias que están asociados a la HF, esto con el fin de identificar la base molecular de la hipercolesterolemia familiar en nuestra población. 


\section{Objetivos}

\subsection{Objetivo general.}

Conocer si el polimorfismo en $A P O B$ (rs5247904) y citocinas proinflamatorias están asociados a la hipercolesterolemia familiar.

\subsection{Objetivos particulares.}

Genotipificar el polimorfismo en el gen $A P O B$ (rs574290) cambio de glutamina por arginina (Ar3500Gln).

Genotipificar polimorfismos en citocinas proinflamatorios CCL1 rs2282691, IL6 rs1818879, TNF rs1800629, TNF rs361525, TNF rs1800750 y CSF2rs25882.

Determinar las frecuencias alélicas y genotípicas de los marcadores genéticos analizados.

\section{$5 \quad$ Hipótesis.}

Los niños y adolescentes con antecedentes de hipercolesterolemia presentarán polimorfismos en APOB y citocinas proinflamatorias que se asocian con la HF. 


\section{$6 \quad$ Material y métodos.}

\subsection{Diseño del estudio}

Tipo del estudio: Observacional, transversal y comparativo, cohorte, casos y controles.

\subsection{Estrategia general}

En el este estudio se incluyeron pacientes y familias con diagnóstico de hipercolesterolemia familiar provenientes del Instituto Nacional de Pediatría y un grupo control con individuos clínicamente sanos, a los cuales se les tomó una muestra de sangre a partir de la cual se obtuvo el suero y se extrajo el ADN. El suero se utilizó para el estudio bioquímico mientras que el ADN se utilizó para el estudio molecular. En la figura 7 se observa el diagrama de la estrategia general empleada en el estudio. 


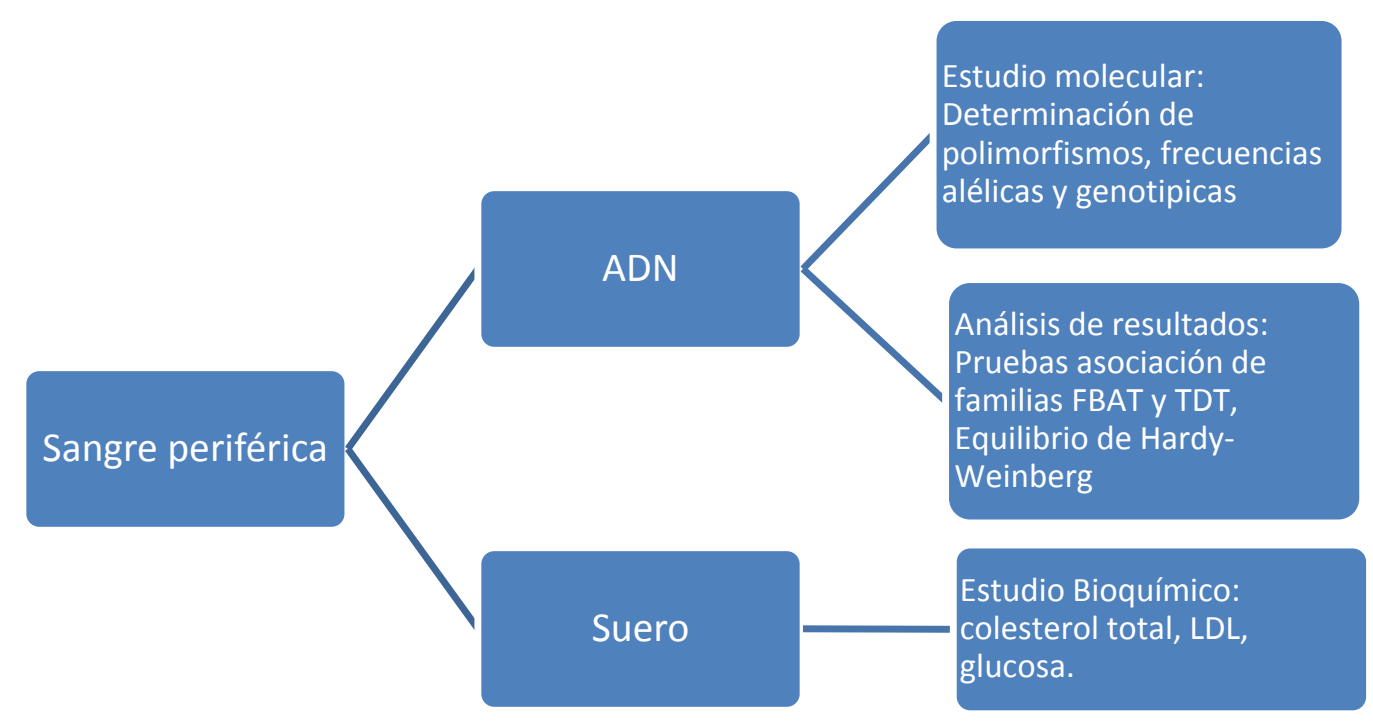

Figura 7. Estrategia general empleada en el presente estudio.

\subsection{Sujetos del estudio}

Pacientes con hipercolesterolemia y familiares cercanos de cualquier género que son atendidos en el Instituto Nacional de Pediatría

Tamaño 11 pacientes y 33 familiares en total 44 casos

Grupo control: sujetos sanos no relacionados de cualquier género a los que se realizó una encuesta y sin evidencia de hipercolesterolemia y procedentes de la UAM-Xochimilco

Tamaño de la muestra: 48 sujetos 


\subsubsection{Criterios de Inclusión}

Pacientes del Servicio de Cardiología del Instituto Nacional de Pediatría que comprenden desde neonatos (0-28 días), lactantes (1 mes-2 años), prescolar (2-6 años), escolar (6-12 años) y adolescentes (12-18 años) de edad. Pacientes que pertenezcan a familias con niveles de colesterol $>240 \mathrm{mg} / \mathrm{dl}$ con antecedentes o no de enfermedad aterosclerótica.

\subsubsection{Criterios de Exclusión}

Pacientes con antecedentes de otras enfermedades: cáncer, enfermedades del sistema nervioso central, pacientes con $\mathrm{VIH}$, pacientes con hepatitis $\mathrm{B}$ y $\mathrm{C}$, diabetes tipo 1, síndrome nefrótico, enfermedades del tejido conjuntivo, pacientes con infecciones severas en los últimos 6 meses, pacientes que tomen tratamientos con fármacos anticonvulsivantes, quimioterápicos, antidepresivos, corticosteroides. Abuso de alcohol o drogas estimulantes.

\section{$7 \quad$ Estudio clínico}

A todos los sujetos, previo consentimiento informado por escrito; fueron citados en ayuno nocturno de 10 horas se realizó exploración física completa e historia clínica completa de cada sujeto. 


\section{Estudio bioquímico}

\subsection{Análisis de lípidos.}

Se recolectó muestra de sangre periférica tratada con EDTA como anticoagulante en tubos Vacutainer. La muestra de sangre se utilizó para medir niveles de colesterol. Todas las medidas fueron procesadas en el Instituto Nacional de Enfermedades Respiratorias. Las concentraciones de colesterol en suero, fue determinado por métodos enzimáticos.

\section{$9 \quad$ Estudio molecular}

\subsection{Extracción de ADN}

La extracción del ADN se realizó en el laboratorio de Biología Experimental de la Universidad Autónoma Metropolitana. Se tomaron $5 \mathrm{ml}$ de sangre periférica de cada individuo en tubos Vacutainer con EDTA al 5\% como anticoagulante. A partir de esta muestra se extrajo el ADN genómico, que consiste en realizar la lisis de eritrocitos, seguida por la lisis de leucocitos para, posteriormente, precipitar las proteínas con $\mathrm{NaCl}$; el ADN se precipitó con etanol absoluto y se lavó con etanol al 70\%, se desecó al aire y se resuspendió con regulador de Tris-EDTA (TE) pH 8.0. Una vez purificado el ADN, éste se cuantificó mediante espectrofotometría a 260 y $280 \mathrm{~nm}$ para calcular su concentración (NanoDrop) ajustando todas las muestras a una concentración de $50 \mathrm{ng} / \mu \mathrm{l}$. Finalmente, se realizaron alícuotas de ADN entre 300-500 $\mathrm{LL}$ con TE (TrisEDTA), las cuales se guardaron a $-70^{\circ} \mathrm{C}$ para su preservación óptima y uso posterior. 
El estudio genético se realizó en el laboratorio de Complejo Principal de Histocompatibilidad (HLA) del Instituto Nacional de Enfermedades Respiratorias Ismael Cosío. Comprende la genotipificación de los polimorfismos en el exón del gen $A P O B$ rs5742904 (Arg3500Gln) y citocinas proinflamatorios CCL1 rs2282691, IL6 rs1818879, TNF rs1800629, TNF rs361525, TNF rs1800750 y CSF2rs25882. La técnica empleada es reacción en cadena de la polimerasa $(P C R)$, en tiempo real usando sondas TaqMan.

\subsection{Identificación de polimorfismos empleando PCR en tiempo real.}

Los polimorfismos de los genes que se analizaron son algunos en los que se ha encontrado asociación con estados de hipercolesterolemia y aterosclerosis.

La reacción en cadena de la polimerasa es una técnica que permite amplificar y al mismo tiempo cuantificar más de mil millones de veces un ADN obtenido. Para llevar acabó la reacción se requiere de un molde de ADN, cebadores, dNTPs, ADN polimerasa, mezcla buffer y sondas marcadas con fluoróforos. El procedimiento de PCR en tiempo real se efectúa en un termociclador, que se basa en una serie de 2540 ciclos con cambios de temperatura y cada ciclo de reacción consta de tres etapas cada uno primero, de $94^{\circ}-96^{\circ} \mathrm{C}$ se desnaturalizan las dos cadenas de $A D N$, segundo en torno de los $50^{\circ}-60^{\circ} \mathrm{C}$ permite la hibridación de los cebadores con sus secuencias complementarias en ambas hebras y tercero entre los $68^{\circ}-72^{\circ} \mathrm{C}$ comienza la polimerización de ADN. En la tabla 2 se muestran los polimorfismos analizados. 
Tabla 2. Polimorfismos de los genes analizados.

\begin{tabular}{|c|c|c|}
\hline Polimorfismo & $\begin{array}{c}\text { Identificación del } \\
\text { SNP }\end{array}$ & Cromosoma \\
\hline APOB C/T & rs5742904 & 2 \\
\hline IL6 A/G & rs1818879 & 7 \\
\hline TNF A/G & rs1800629 & 6 \\
\hline TNF A/G & rs361525 & 6 \\
\hline TNF A/G & rs1800750 & 6 \\
\hline CCL1 A/T & rs2282691 & 17 \\
\hline
\end{tabular}

La PCR en tiempo real requiere de sondas marcados doblemente con fluorocromos uno en su extremo 3'y una molécula en 5'que bloquea la emisión de fluorescencia, esto permite medir la producción de productos de PCR generados. Las sondas hibridan específicamente en una secuencia complementaria y emiten fluorescencia que directamente proporcional a la cantidad de amplicón producido, si la sonda no hibrida la molécula en 5'absorbe la fluorescencia. Las sondas comerciales empleadas para este trabajo fueron las Ilamadas TaqMan que constan de doble marcaje una para el alelo 1 VIC (verde) y otra para el alelo 2 FAM (rojo).

\subsection{Procedimiento para realizar la PCR}

Para realizar la genotipificación de polimorfismos del exón 26 para APOB y citocinas proinflamatorias se optimizaron los parámetros de la PCR como son: concentración 
de ADN, sondas comerciales TaqMan, master mix (contiene $\mathrm{MgCl}_{2}, \mathrm{KCl}$, dNTPs y Taq polimerasa) y $\mathrm{H}_{2} \mathrm{O}$ cbp $5 \mu$ l. Para establecer las condiciones de amplificación se realizaron experimentos con varias concentraciones de ADN y reactivos. El equipo empleado es 7300 Real Time PCR System de Applied Biosystems. A continuación se ilustran los pasos experimentales realizados para analizar los marcadores genéticos en el gen APOB y citocinas proinflamatorias.

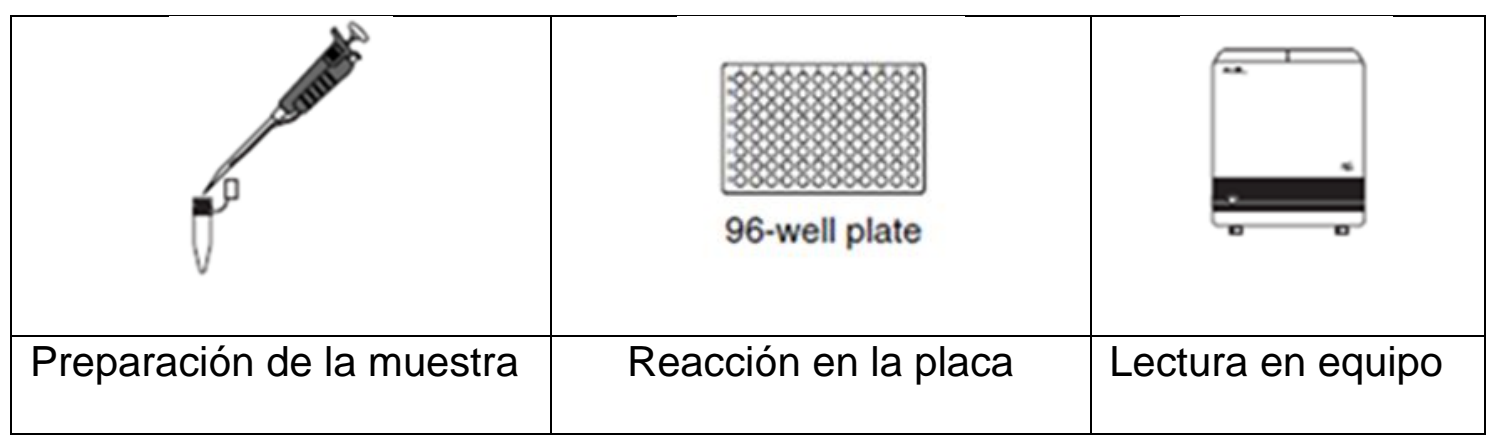

Para la amplificación de los fragmentos donde se encuentran los polimorfismos de interés se preparó un volumen final de reacción de $5 \mu \mathrm{l}$, a las concentraciones finales

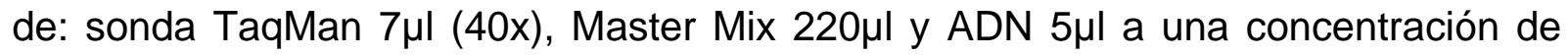
15ng/ $\mu$ l de ADN genómico. Los componentes de la reacción y sus concentraciones se observan en la tabla 3. 
Tabla 3. Preparación de la placa con 96 pozos para la reacción de PCR-TR

\begin{tabular}{|l|l|}
\hline Componentes & \multicolumn{1}{|c|}{ Concentración } \\
\hline ADN $15 \mathrm{ng} / \mu \mathrm{l}$ & $5 \mu \mathrm{l}$ \\
\hline Sonda TaqMan 40X & $7 \mu \mathrm{l}$ \\
\hline Master Mix & $220 \mu \mathrm{l}$ \\
\hline $\mathrm{H}_{2} \mathrm{O}$ & $290 \mu \mathrm{l}$ \\
\hline Volumen final & 522 \\
\hline
\end{tabular}

\subsection{Interpretación de graficas de resultado de PCR en tiempo real.}

Los resultados obtenidos de la PCR en tiempo real fueron interpretados por medio de gráficas que representan si en la muestra se encuentran homocigotos 0 heterocigotos. Esto se realiza por medio de curvas de amplificación que emplea un sistema de detección que se basa en dos sondas, marcadas con un fluoróforo distinto cada una, uno llamado VIC verde para el alelo 1 y FAM rojo para el alelo 2. En la figura 8 se observa un gráfico con la muestra de un heterocigoto ya que se visualiza la amplificación de ambos detectores. 




Figura 8. Gráfica de amplificación de PCR a tiempo real. El eje vertical representa la cantidad de fluorescencia normalizada, $y$ el eje horizontal el número de ciclos. 


\section{Resultados}

Este estudio consistió en una investigación de carácter multinstitucional, en el cual participaron la Universidad Autónoma Metropolitana-Iztapalapa (UAM), el Instituto Nacional de Pediatría (INP) y el Instituto Nacional de Enfermedades Respiratorias (INER). Se analizaron 11 pacientes con hipercolesterolemia familiar de los cuales 6 son hombres y 5 son mujeres con edades comprendidas entre los 2 y 18 años, el grupo de los familiares de los casos se analizaron 33 individuos su promedio de edad fue de 39 años y para el grupo control 48 individuos con un promedio de edad de 24 años. Las tablas 4 y 4bis se describen las características clínicas y bioquímicas de los pacientes del estudio.

Las características clínicas y bioquímicas de los casos se describen en las siguientes tablas.

Tabla 4. Características clínicas y bioquímicas de pacientes con HF del Instituto Nacional de Pediatría.

\begin{tabular}{|l|l|l|l|l|l|}
\hline Parametro & Paciente 1 & Paciente 2 & Paciente 3 & Paciente 4 & Paciente 5 \\
\hline Edad años & 2 & 3 & 3 & 6 & 9 \\
\hline Sexo & $\mathrm{F}$ & $\mathrm{F}$ & $\mathrm{M}$ & $\mathrm{M}$ & $\mathrm{M}$ \\
\hline $\mathrm{IMC}$ & 14 & 15 & 15.6 & 14.2 & 14.2 \\
\hline $\begin{array}{l}\text { Colesterol } \\
\mathrm{mg} / \mathrm{dl}\end{array}$ & 240 & 213 & 290 & 336 & 194 \\
\hline LDL mg/dl & 162.1 & 157.8 & 128 & 120 & 126 \\
\hline HDL mg/dl & 29.4 & 32.4 & 52 & 30.9 & 52 \\
\hline $\begin{array}{l}\text { Glucosa mg/dl } \\
\text { Xantomas }\end{array}$ & $\mathbf{N}$ & 86 & 74 & 85 & 109 \\
\hline Arco corneal & No & No & Si & No & No \\
\hline Tratamiento & Atorvastatina & Dieta & Dieta & Simvastati- & Dieta \\
\hline & & & & na &
\end{tabular}


Tabla 4 bis. Características clínicas y bioquímicas de pacientes con HF del Instituto Nacional de Pediatría.

\begin{tabular}{|c|c|c|c|c|c|c|}
\hline Parametro & Pacient 6 & Pacient 7 & Pacient 8 & Pacient 9 & Pacient 10 & Pacient 11 \\
\hline Edad & 9 & 10 & 10 & 13 & 14 & 18 \\
\hline Sexo & $M$ & $\mathrm{~F}$ & $M$ & $\mathrm{~F}$ & $M$ & $\mathrm{~F}$ \\
\hline IMC & 15.2 & 13.2 & 15.4 & 17 & 24.1 & 22.1 \\
\hline $\begin{array}{l}\text { Colesterol } \\
\mathrm{mg} / \mathrm{dl}\end{array}$ & 927 & 200 & 173 & 205 & 226 & 429 \\
\hline $\mathrm{LDL} \mathrm{mg} / \mathrm{dl}$ & 839.4 & 142.6 & 138 & 148 & 156 & 388 \\
\hline $\mathrm{HDL} \mathrm{mg/dl}$ & 26.6 & 24.3 & 30.1 & 29.1 & 21.7 & 19.7 \\
\hline $\begin{array}{l}\text { Glucosa } \\
\mathrm{mg} / \mathrm{dl}\end{array}$ & 77 & 90 & 89 & 76 & 85 & 87 \\
\hline Xantomas & $\mathrm{Si}$ & No & No & No & No & No \\
\hline $\begin{array}{l}\text { Arco } \\
\text { corneal }\end{array}$ & $\mathrm{Si}$ & No & No & No & No & No \\
\hline Tx & $\begin{array}{l}\text { Atorvasta. } \\
\text { Aféresis de } \\
\text { LP }\end{array}$ & Dieta & Dieta & $\begin{array}{l}\text { Atorvasta- } \\
\text { tina }\end{array}$ & Dieta & $\begin{array}{l}\text { Lovastati- } \\
\text { na }\end{array}$ \\
\hline
\end{tabular}

Para poder realizar análisis y comparar el grupo de pacientes y sus familiares con el grupo control se hicieron las mismas pruebas que los pacientes. Con objeto de comparación se analizaron 33 familiares y 48 controles sujetos sanos.

En la tabla 5 se muestran los datos demográficos del grupo control, casos y sus familias. Se describe la edad, peso y niveles de colesterol total. El dato que muestra diferencia son los niveles de colesterol total el grupo control muestra una mediana de $174 \mathrm{mg} / \mathrm{dl}$ contra el grupo de casos con $298 \mathrm{mg} / \mathrm{dl}$ y las familias con $205 \mathrm{mg} / \mathrm{dl}$. 
Tabla 5. Datos demográficos de controles, casos y sus familias

\begin{tabular}{|l|l|l|l|}
\hline $\begin{array}{l}\text { Grupo } \\
\text { control } \\
\mathbf{n}=\mathbf{4 8}\end{array}$ & $\begin{array}{l}\text { Mediana } \\
\text { (min-max) }\end{array}$ & $\begin{array}{l}\text { Casos } \\
\mathbf{n = 1 1}\end{array}$ & $\begin{array}{l}\text { Familiares } \\
\mathbf{n}=33\end{array}$ \\
\hline Edad (años) & $24(21-36)$ & $8(18-2)$ & $39(77-3)$ \\
\hline Peso (kg) & $56(48-77)$ & $30(63-9)$ & $63(85-16)$ \\
\hline $\begin{array}{l}\text { Colesterol } \\
\text { (mg/dl) }\end{array}$ & $\begin{array}{l}174(126- \\
199)\end{array}$ & $\begin{array}{l}298(184- \\
927)\end{array}$ & $\begin{array}{l}205(385- \\
161)\end{array}$ \\
\hline
\end{tabular}

\subsection{Herencia genética representada por medio de árboles genealógicos}

El árbol genealógico es uno de los primeros pasos a llevar a cabo en el diagnóstico de enfermedades. Consiste en la representación gráfica de la historia clínica familiar. Está representación facilita la identificación de síndromes genéticos y el establecimiento de diagnósticos presintomáticos. A su vez permite un mejor cálculo del riesgo (recurrencia u ocurrencia) y los patrones de herencia de una enfermedad, es decir, permite conocer la probabilidad de tener una enfermedad o de heredarla.

Se elaboró para cada paciente su árbol genealógico para poder construir y reconocer si hay patrones de herencia que puedan indicar la presencia de hipercolesterolemia de quién ha estado afectado y quién puede estar afectado actualmente (individuos estudiados) y en el futuro. 
A continuación se muestra en la figura 9 los árboles genealógicos de cada paciente que se estudió, el círculo representa al sexo femenino, el cuadrado al sexo masculino, las figuras iluminadas a los afectados por la enfermedad y la flecha indica al sujeto en estudio.
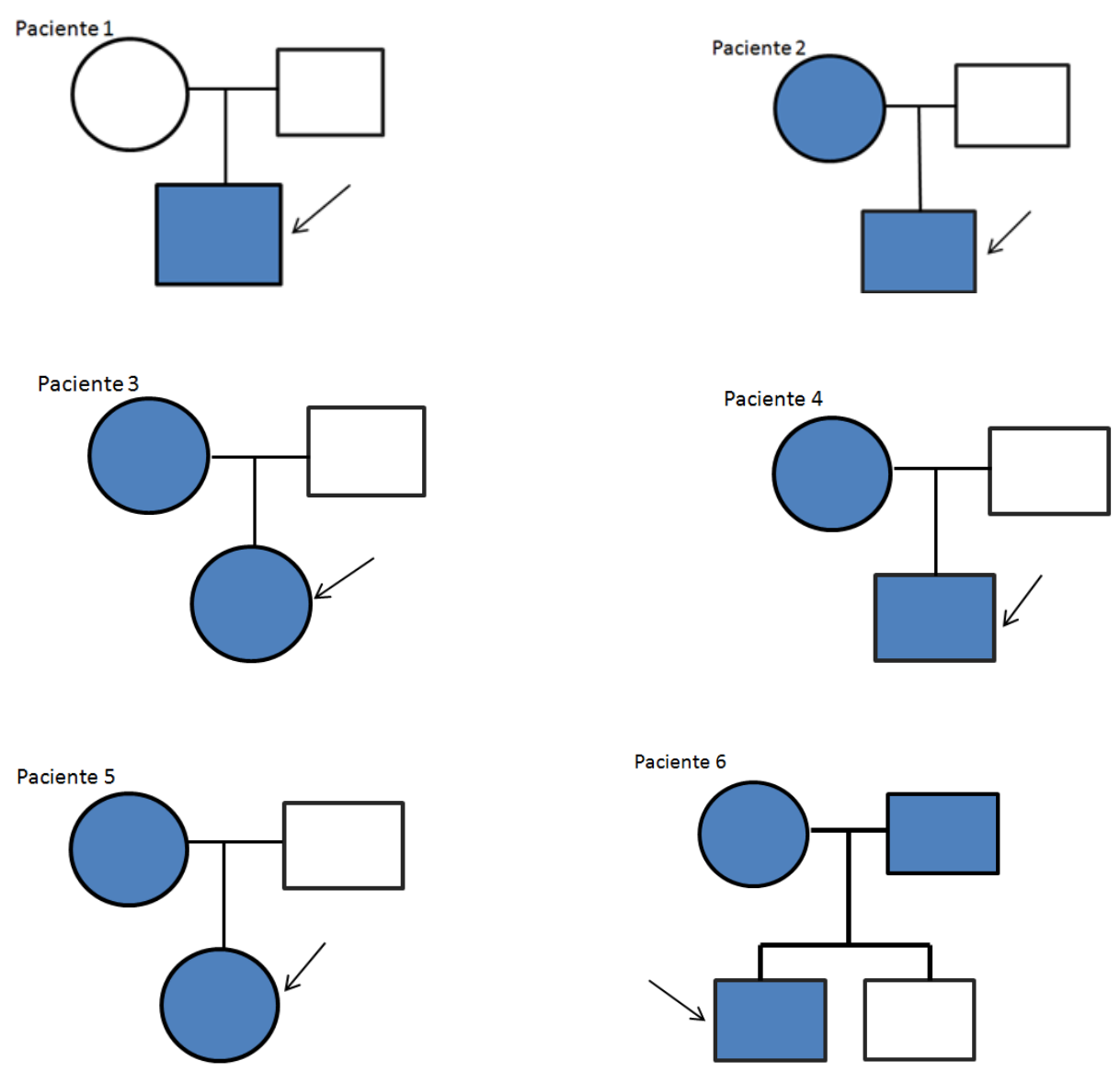

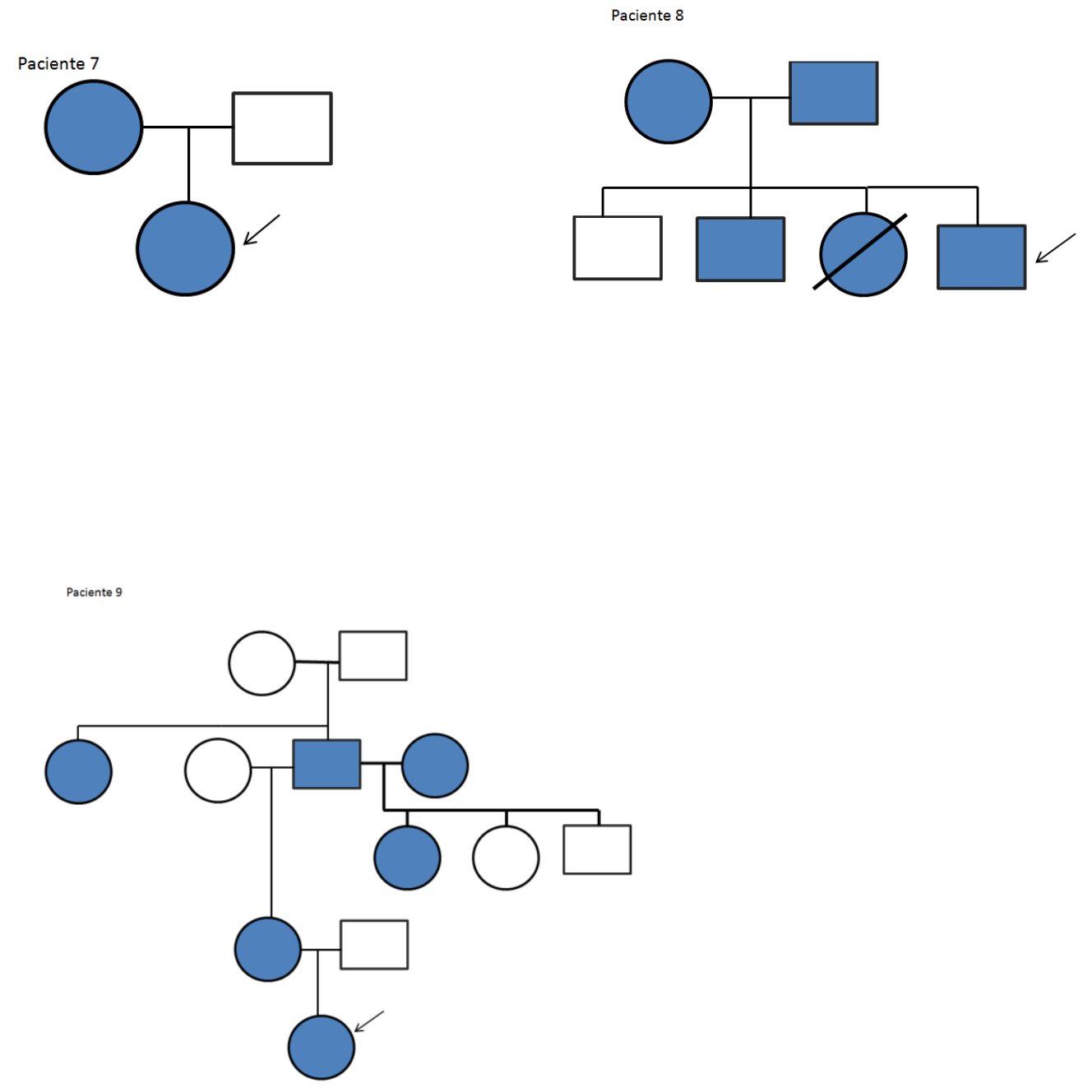

Paciente 10

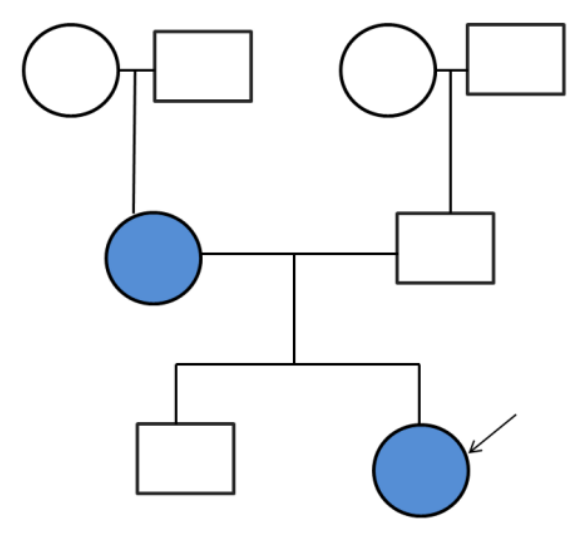




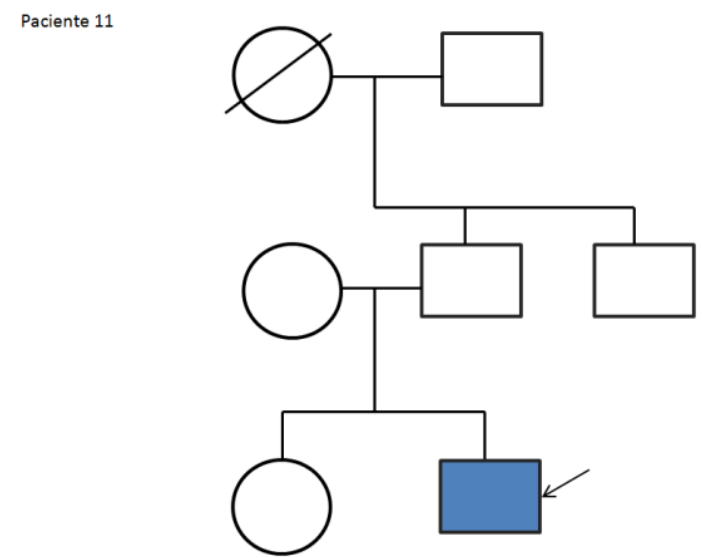

Figura 9. Árboles genealógicos de cada paciente, en los cuales se muestran los patrones de herencia. Para el paciente 1 y 11 en este caso son los únicos afectados por la enfermedad, para los pacientes 2, 3, 4, 5, 7 y 10 la madre también está afectada, para el paciente 6 ambos padres están afectados, para el paciente 8 solo un hermano no está afectado, ambos padres un hermano están afectados también se observa el fallecimiento por la enfermedad de una hermana representado por una línea diagonal y para el paciente 9 están afectados madre, abuelo, tía y primo.

\subsection{Genotipificación}

Una vez genotipificadas las variantes alélicas del gen APOB (rs5742904) y de las citocinas proinflamatorias se halló que no hay diferencia entre las muestras de los pacientes, sus familiares y los controles.

En las siguientes gráficas se muestran resultados de la PCR, las sondas TaqMan empleadas están marcadas con doble fluorescencia con un detector y un silenciador. Un marcaje es para el alelo 1 llamado VIC en verde y otro marcado para el alelo 2 
FAM en rojo. En las figuras 10 y 11 se muestran algunos gráficos de los resultados obtenidos para ApoB100 y citocina CFS2.

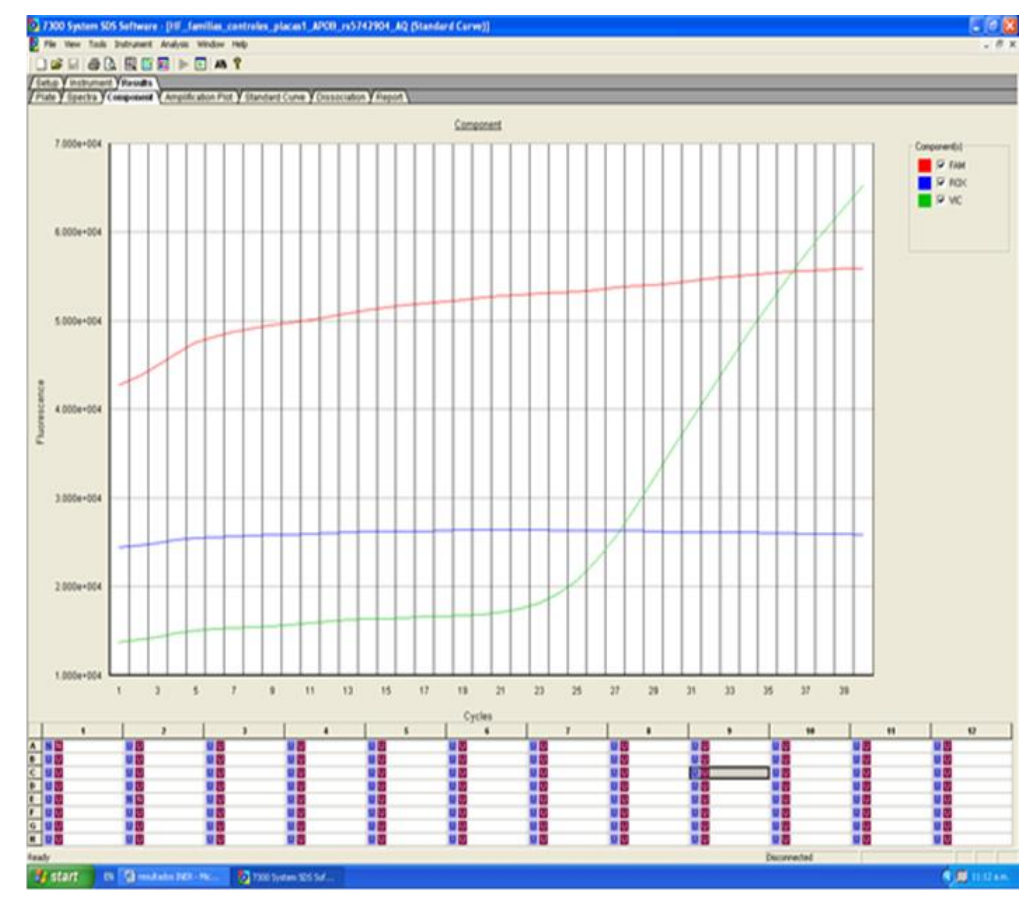

Figura 10. En esta gráfica se presenta el resultado para el marcador genético del gen ApoB100 (rs5247904), se observa marcaje de VIC en verde que indica que es un homocigoto. 


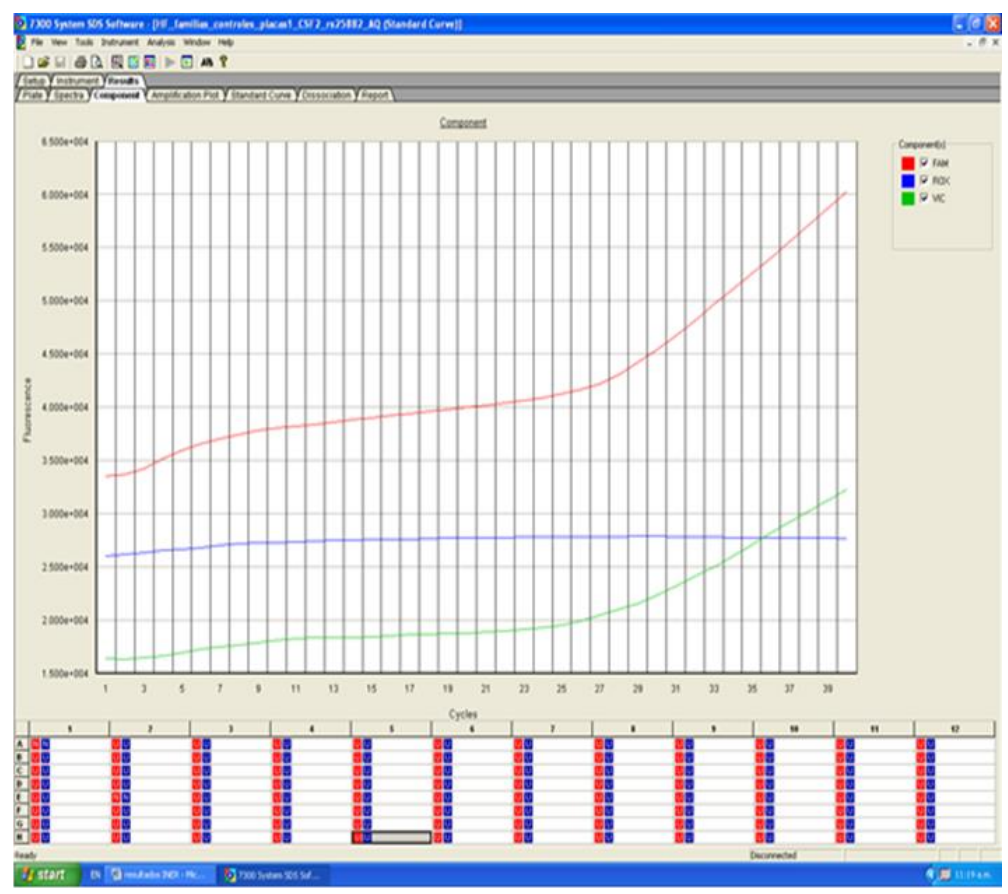

Figura 11. En esta gráfica se presenta el resultado del marcador genético para CFS2 (rs25882), se observa marcaje de los dos fluróforos que indican que es heterocigoto.

\subsection{Análisis estadístico.}

Las pruebas para analizar familias, fueron la prueba basada en asociación de familias (FBAT) y prueba de desequilibrio de transmisión (TDT). Estas pruebas evalúan la probabilidad de que un fenotipo de interés y un marcador genético en particular o una serie de marcadores sean transmitidos juntos a través de múltiples generaciones. Los tríos consisten en un padre, una madre y un hijo afectado. Para analizar las familias de este estudio se optó por la prueba FBAT ya que evalúa familias en las cuales falta algún padre y también se pueden incluir más miembros de la familia como hermanos, tíos. La fig. 12 muestra cómo se forman los tríos, en este 
ejemplo se formaron tres tríos el primero incluye un hijo afectado y a la madre, el segundo y tercer trío incluye al hijo afectado y sus padres.



Fig. 12. Formación de tríos en la prueba FBAT. 


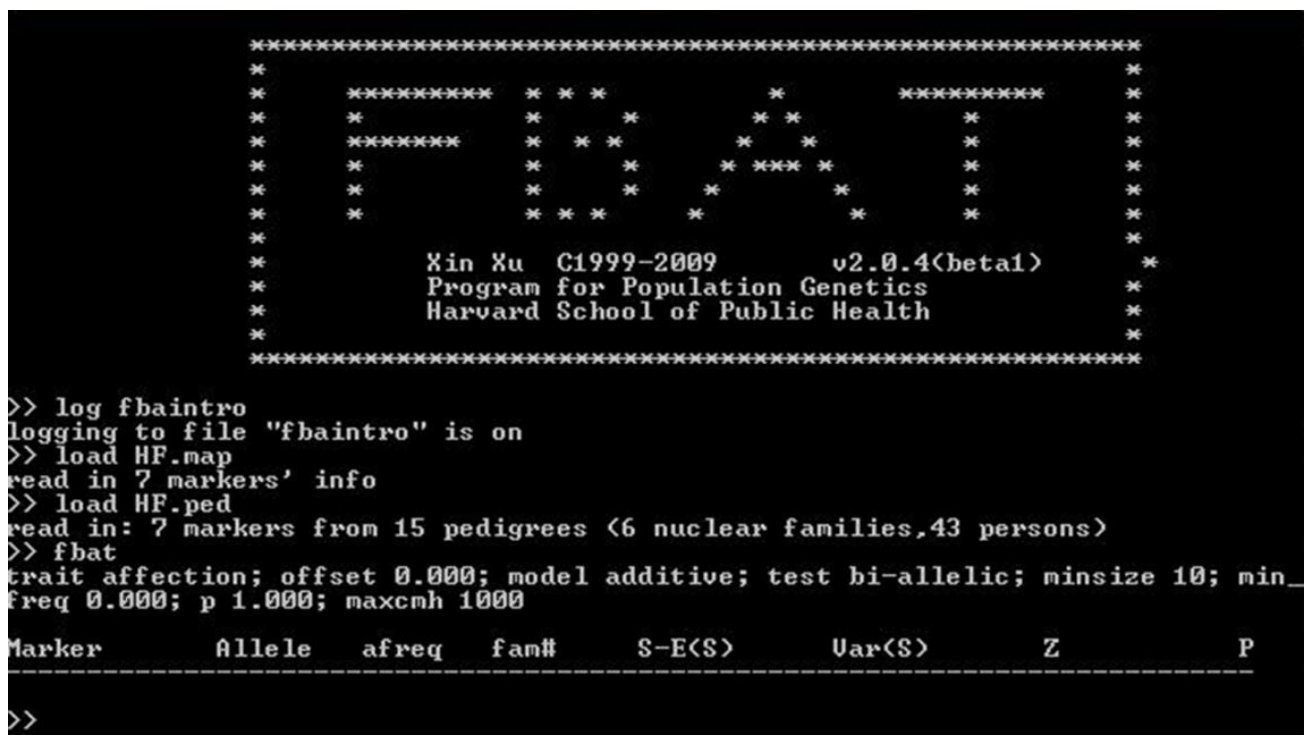

Los resultados obtenidos de la prueba FBAT no muestran asociación de desequilibrio en la transmisión.

La prueba TDT sólo se corrió para corroborar algunos datos de la prueba de FBAT. En la tabla 6 se muestran los resultados y como se puede observar conserva los mismos resultados para la prueba de FBAT, para la razón de momios no hay riesgo y el valor de $p$ no es significativo.

Tabla 6. Prueba TDT empleando software plink 1.07

\begin{tabular}{|c|c|c|c|c|}
\hline CHR & SNP & BP & OR & $P$ \\
\hline 2 & rs5742904 & 21229160 & NA & NA \\
\hline 5 & rs25882 & 131411460 & NA & 0.1573 \\
\hline 6 & $\mathrm{rs} 1800750$ & 31542963 & NA & NA \\
\hline 6 & rs1800629 & 31543031 & NA & NA \\
\hline 6 & rs361525 & 31543101 & 0 & 0.3173 \\
\hline 7 & $\mathrm{rs} 1818879$ & 22772727 & 0.6667 & 0.6547 \\
\hline 17 & $\mathrm{rs} 2282691$ & 32688309 & 1 & 1 \\
\hline
\end{tabular}




\subsection{Equilibrio de Hardy-Weinberg}

El principio de Hardy-Weinberg establece una distribución aleatoria de genotipos y por tanto un equilibrio genético de una población en ausencia de selección, mutación y/o migración. Para determinar si las frecuencias genotípicas están dentro de los valores esperados en base a las frecuencias alélicas encontradas y saber si se encuentran en equilibrio de Hardy-Weinberg, se utilizó el software Pink 1.07 que genera datos de genotipo/fenotipo, la tabla 7 muestra la transmisión de las generaciones y se muestra que cumple con el equilibrio en el caso del grupo de casos y familias.

Tabla 7. Equilibrio de Hardy-Weinberg en familias

\begin{tabular}{|l|r|r|r|r|l|l|}
\hline Name & Position & HWpval & \%Geno & MAF & Alleles & Rating \\
\hline rs5742904 & 21229160 & 1 & 100 & 0 & C:C & BAD \\
\hline rs1818879 & 22772727 & 0.9858 & 100 & 0.38 & A:G & \\
\hline rs1800750 & 31542963 & 1 & 100 & 0 & G:G & BAD \\
\hline rs1800629 & 31543031 & 1 & 100 & 0.02 & G:A & \\
\hline rs361525 & 31543101 & 1 & 100 & 0.04 & G:A & \\
\hline rs2282691 & 32688309 & 1 & 100 & 0.2 & T:A & \\
\hline rs25882 & 131411460 & 1 & 100 & 0.22 & T:C & \\
\hline
\end{tabular}

Las frecuencias alélicas y genotípicas de los marcadores genéticos para el gen $A P O B$ y citocinas proinflamatorias analizados muestran que las frecuencias permanecen constantes de una generación a otra, y de acuerdo con la información reportada en estudios en diferentes poblaciones caucásicas no muestra variación en ningún alelo, es decir, se conserva constante la frecuencia tanto del alelo menor como la del alelo mayor. Para que pueda ser reportado como un polimorfismo la frecuencia del alelo menor (MAF) debe ser al menos del 1\%. En las tablas 8 y 9 se describen los resultados del grupo control, casos y familias. 
Tabla 8. Frecuencias alélicas del grupo control

\begin{tabular}{|l|l|l|l|l|l|l|}
\hline Gen & Cr & SNP & Cambio & $\begin{array}{l}\text { Alelo } \\
\text { ancestral }\end{array}$ & $\begin{array}{l}\text { Alelo } \\
\text { menor }\end{array}$ & MAF \\
\hline CCL1 & 17 & rs228269 & A/T & T & A & 0.30 \\
\hline CSF2 & 5 & rs25882 & C/T & T & C & 0.20 \\
\hline IL6 & 7 & rs1818879 & A/G & G & G & 0.24 \\
\hline APOB & 2 & rs5742904 & C/T & C & T & 0.00 \\
\hline TNF629 & 6 & rs1800629 & A/G & G & A & 0.07 \\
\hline TNF25 & 6 & rs361525 & A/G & G & A & 0.08 \\
\hline TNF750 & 6 & rs1800750 & A/G & G & A & 0.00 \\
\hline
\end{tabular}

Tabla 9. Frecuencias alélicas de casos y familias

\begin{tabular}{|l|l|l|l|l|l|l|}
\hline Gen & Cr & SNP & Cambio & $\begin{array}{l}\text { Alelo } \\
\text { ancestral }\end{array}$ & $\begin{array}{l}\text { Alelo } \\
\text { menor }\end{array}$ & MAF \\
\hline CCL1 & 17 & rs228269 & A/T & T & A & 0.25 \\
\hline CSF2 & 5 & rs25882 & C/T & T & C & 0.22 \\
\hline IL6 & 7 & rs1818879 & A/G & G & G & 0.37 \\
\hline APOB & 2 & rs5742904 & C/T & C & T & 0.00 \\
\hline TNF 629 & 6 & rs1800629 & A/G & G & A & 0.03 \\
\hline TNF25 & 6 & rs361525 & A/G & G & A & 0.03 \\
\hline TNF750 & 6 & rs1800750 & A/G & G & A & 0.00 \\
\hline
\end{tabular}


Las frecuencias genéticas encontradas en $A P O B$ y citocinas proinflamatorias muestran relación directa con lo reportado para las frecuencias alélicas, se conserva la transmisión constante de generación en generación en la tabla 10 se describen las frecuencias genotípicas. La MAF reportada para ambos casos es menor al 1\%, por lo tanto no se considera un polimorfismo.

Tabla 10. Frecuencias genotípicas de casos y controles

\begin{tabular}{|l|l|l|}
\hline Gen & Genotipo controles & Genotipo casos \\
\hline CCL1 & TT 21, TA 21, AA 3 & TT 24, TA 15, AA 3 \\
\hline CSF2 & TT 28, TC 16, CC 1 & TT 26, TC 16, CC 1 \\
\hline IL6 & AA 26, AG 16, GG 3 & AA 16, AG 22, GG 5 \\
\hline APOB & CC 43, CT 0, TT 0 & CC 44, CT 0, TT 0 \\
\hline TNF 29 & GG 39, GA 6, AA 0 & GG 42, GA 2, AA 0 \\
\hline TNF 25 & GG 37, GA,7 AA 0 & GG 42, GA 2, AA 0 \\
\hline TNF 750 & GG 33, GA 0, AA 0 & GG 40, GA 0, AA 0 \\
\hline
\end{tabular}




\section{Discusión de resultados.}

Los resultados obtenidos para el polimorfismo del gen APOB100 R3527Q (rs5247904), indican que el genotipo CC no se encuentra asociado con el desarrollo de hipercolesterolemia familiar en la población estudiada ya que el resultado muestra que la frecuencia del alelo menor (MAF) es de él $0 \%$, mientras que los genotipos de mayor riesgo podrían ser TC o TT para el desarrollo de hipercolesterolemia. En el caso de los polimorfismos para las citocinas proinflamatorias los genotipos encontrados fueron: IL-6 AA, TNF GG, CCL1 TT y CSF2 TT, los cuales tampoco indican riesgo ya que presentan una MAF menor del $1 \%$.

En estudios hechos en Europa central se han reportado como causa probable de hipercolesterolemia familiar al polimorfismo localizado en el gen de $A P O B 100$ en el residuo R3527Q con cambio de glutamina por arginina, que disminuye la afinidad de la apolipoproteína al receptor LDL-c, causando acumulación de partículas de LDL en el torrente sanguíneo, en el estudio de Chmara et al. 2010 de 378 participantes seleccionados 25 casos portaron el polimorfismo en el gen $A P O B$ R3527Q. En el estudio de Chatzistefanidis et al. 2013 reportaron el caso de una familia que porta el polimorfismo para ApoB100, mientras que otros autores como Miserez y Fisher 2000, han reportado la prevalencia de este polimorfismo en el centro de Europa y su expansión por la migración al resto del continente. Fouchier et al. 2005; Brusgaard et al. 2006; Civeira et al. 2008 reportan que R3527Q es la más común y también utilizan menos criterios de inclusión para ampliar el número de pacientes y posibles polimorfismos nuevos. Lombardi et al. 2000; Kalina et al. 2001 reportaron que el 
polimorfismo más común era $\mathrm{R} 3527 \mathrm{Q}$, que normalmente representa el 2-5\% de los pacientes con hipercolesterolemia familiar.

En un estudio realizado en el IMSS por Vaca et al. 2011 se analizaron 62 casos y 269 individuos familiares de los casos, encontraron cinco nuevos polimorfismos para el receptor de LDL, y solo un polimorfismo para $A P O B 100$ en el nucleótido 3560 que es cambio de glutamina por arginina, que representaría un nuevo polimorfismo encontrado en nuestra población con diferencia de los reportados por otros estudio como los del continente europeo, por lo tanto este estudio del IMSS coincide con el reportado en este estudio.

Se han encontrado citocinas proinflamatorias en pacientes con aterosclerosis y que han sufrido infarto agudo de miocardio como lo demuestra el estudio de Domínguez et al. 2003, donde analizan los niveles de IL-6 y esta fue significativamente mayor en los pacientes con infarto agudo de miocardio que en los controles. Otro estudio Lorenzo et al. 2009 demuestra que el TNF desempeña un papel clave en la formación y la progresión de la placa aterosclerótica. Charakida et al. 2009 realizaron un estudio con 38 niños con hipercolesterolemia familiar y encontraron que tanto IL-6 como TNF participan en la formación de la placa y al desarrollo de alteraciones inflamatorias y hemostáticas que están presentes en los niños con $\mathrm{FH}$ y contribuyen a la disfunción endotelial observada en estos niños.

Con base en los resultados obtenidos primero, los casos índice presentan características clínicas y bioquímicas que apoyan el diagnóstico de hipercolesterolemia y en 9 de las 11 familias estudiadas hay correlación de los 
resultados bioquímicos entre los casos y sus padres lo cual orienta a que existe un factor de transmisión hereditaria, segundo no se encontró algún polimorfismo en el gen para $A P O B 100$ (rs5247904) que esté asociado a la enfermedad lo cual coincide con información de otros reportes por lo tanto los polimorfismos en el gen $A P O B$ no son una causa común de HF en México y la causa genética podría ser debido a polimorfismos en los genes del receptor LDLR principalmente. Para las citocinas proinflamatorias no se encontraron polimorfismos asociados con HF ni con desarrollo precoz de aterosclerosis. En las frecuencias alélicas que reportamos para nuestros casos índice al compararlas con nuestros controles y las reportadas en otras poblaciones en específico la caucásica se confirma que no existe asociación entre enfermedad y presenta transmisión conservada de generación en generación y por lo tanto cumple el equilibrio de Hardy-Wienberg. Los resultados alcanzados, la importancia y aportación de este trabajo dejan de antecedente y apoyado con otra publicación reciente del IMSS que algunos polimorfismos para el gen $A P O B$ (rs5247904) y citocinas proinflamatorias, no tienen asociación en la enfermedad de hipercolesterolemia familiar y también da un acercamiento más claro de la proximidad de la base molecular de la hipercolesterolemia en nuestra población para implementar protocolos probablemente enfocados a incluir otros análisis moleculares para ampliar el estudio.

De acuerdo con los resultados anteriores, se demuestra que los pacientes presentan niveles de colesterol arriba del percentil 90 para su edad y género lo que indica riesgo alto para desarrollar aterosclerosis prematura. Los pacientes que están bajo 
tratamiento con estatinas no han presentado mejoría en la reducción de niveles de colesterol lo cual puede ser indicación de que podría existir una causa de falla ya sea a nivel de receptor celular o en el transportador de LDL. En las tablas también se puede evidenciar que todos los pacientes presentan índice de masa corporal (IMC) normal y en algunos casos hasta peso bajo para su edad y estatura lo que indica que los niveles altos de colesterol no son consecuencia de sobrepeso u obesidad sino de una falla clara en su metabolismo y un problema interno de carácter hereditario.

El objetivo fue identificar casos índice y sus familias con hipercolesterolemia familiar para conocer la frecuencia alélica de polimorfismos en el gen APOB (rs5247904) y citocinas proinflamatorias asociados a esta enfermedad, con la intención de proporcionar tratamiento oportuno así como para tratar de aproximar la diversidad de polimorfismos en el exón 26 de la APOB (rs5247904) y citocinas proinflamatorias. Este conocimiento es importante para correlacionar el genotipo-fenotipo de las familias y para optimizar el tratamiento para reducir el colesterol y poder establecer protocolos de análisis de polimorfismos y comprender la base molecular de la HF en México.

El estudio de los pacientes y sus familias mediante procedimientos clínicos y bioquímicos tiene carácter preventivo en pacientes con enfermedades hereditarias para identificar algún otro miembro afectado de la familia esto con el objetivo de dar tratamiento y consejo genético tempranos. De los once pacientes con HF reclutados y sus familias estudiadas se han identificado características clínicas y bioquímicas de carácter hereditario lo cual es de suma importancia para clasificar correctamente a 
este tipo de enfermedad. Se espera que la detección temprana y el tratamiento a largo plazo sea reducir y prevenir el alto riesgo de enfermedad cardiovascular, principalmente en niños y jóvenes individuos, y aumentar la esperanza de vida en estos pacientes. 


\section{Conclusiones.}

Los resultados obtenidos del análisis de los polimorfismos en APOB (rs5247904) y citocinas proinflamatorias CCL1 (rs2282691), IL6 (rs1818879), TNF (rs1800629), TNF (rs361525), TNF (rs1800750) y CSF2 (rs25882), se puede concluir que estos no se encontraron asociados con el desarrollo de hipercolesterolemia y aterosclerosis para la población estudiada. 


\section{Bibliografía}

Aguilar Salinas C, Gómez Díaz R, Gómez Pérez F. Dislipidemias de lo clínico a lo molecular. Lipoproteínas. pág. 3-4 2008.

Arraíz R.N. Alteraciones en genes del metabolismo lipídico y enfermedad cardiovascular. AVFT 26(1):1-9. 2007.

Arraíz R. N, Prieto, C., Toledo, A., Mujica, E., Bello, L., Pacheco, M., \& Escalona, C. (2011). Mutaciones en la región codificante del dominio de unión de la apolipoproteina B-100: diagnóstico de apolipoproteína B defectuosa familiar. Revista Latinoamericana de Hipertensión, 6(2), 30-34.

Akl C Fahed y Georges M Nemer. Familial Hypercholesterolemia: The Lipids or the Genes? Nutrition \& Metabolism ,8:23. 2011

Borén, J., Ekström, U., Ågren, B., Nilsson-Ehle, P., \& Innerarity, T. L. (2001). The molecular mechanism for the genetic disorder familial defective apolipoprotein B100. Journal of Biological Chemistry, 276(12), 9214-9218.

Brusgaard, K., Jordan, P., Hansen, H., Hansen, A. B., \& Hørder, M. (2006). Molecular genetic analysis of 1053 Danish individuals with clinical signs of familial hypercholesterolemia. Clinical genetics, 69(3), 277-283.

Charakida, M., Tousoulis, D., Skoumas, I., Pitsavos, C., Vasiliadou, C., Stefanadi, E., \& Stefanadis, C. (2009). Inflammatory and thrombotic processes are associated with vascular dysfunction in children with familial hypercholesterolemia. Atherosclerosis, 204(2), 532-537. 
Chatzistefanidis, D., Markoula, S., Vartholomatos, G., Milionis, H. J., Miltiadous, G., Georgiou, I., \& Kyritsis, A. P. First Detection of Hypercholesterolemia Causing ApoB100 R3527Q Mutation in a Family in Greece. J Genet Syndr Gene Ther, 4(155), 2013.

Checa caratachea. Polimorfismos genéticos: Importancia y aplicaciones. Rev Inst Nal Enf Resp Mex. (20), 213-221. 2007

Chmara, M., Wasąg, B., Żuk, M., Kubalska, J., Węgrzyn, A., Bednarska-Makaruk, M., \& Limon, J. (2010). Molecular characterization of Polish patients with familial hypercholesterolemia: novel and recurrentLDLR mutations. Journal of applied genetics, 51(1), 95-106.

Civeira, F., Ros, E., Jarauta, E., Plana, N., Zambon, D., Puzo, J., \& Pocovi, M. (2008). Comparison of genetic versus clinical diagnosis in familial hypercholesterolemia. The American journal of cardiology, 102(9), 1187-1193.

Cordell HJ, Clayton DG. Genetic association studies. Lance;366:1121-1131. 2005

Damon A Bell, Amanda J Hooper, Gerald F Watts, John R Burnett. Mipomersen and other therapies for the treatment of severe familial hypercholesterolemia. Vascular Health and Risk Management. 2012:8 651-659. 2012

Domínguez Rodríguez, A., Abreu González, P., García, M. J., de la Rosa, A., Vargasa, M., \& Marrero, F. (2003). Ritmo luz/oscuridad de las citocinas proinflamatorias en el infarto agudo de miocardio. Revista española de cardiología, 56(6), 555-560. 
Ejarque, I., Real, J. T., Ascaso, J. F., Chaves, F. J., Milian, E., Priego, M. A., \& Carmena, R. (2004, July). Estudio de los valores plasmáticos de Lp (a) en el defecto familiar de unión de la apo B 100 en una población mediterránea del sur de Europa. In Anales de Medicina Interna (Vol. 21, No. 7, pp. 14-19). Arán Ediciones, SL.

Engler, M. M., Engler, M. B., Malloy, M. J., Chiu, E. Y., Schloetter, M. C., Paul, S. M., \& Mietus-Snyder, M. (2003). Antioxidant vitamins C and E improve endothelial function in children with hyperlipidemia endothelial assessment of risk from lipids in youth (EARLY) Trial. Circulation, 108(9), 1059-1063.

Fisher, E., Groß, W., \& März, W. (2000). High Prevalence of FDB< sub> $3500 \mathrm{Q}</$ sub $>$ mutation in the Swiss population. Atherosclerosis, 153(2), 519-521.

Fisher, E., Scharnagl, H., Hoffmann, M. M., Kusterer, K., Wittmann, D., Wieland, H., \& März, W. (1999). Mutations in the apolipoprotein (apo) B-100 receptor-binding region: detection of apo B-100 (Arg3500 $\rightarrow$ Trp) associated with two new haplotypes and evidence that apo B-100 (Glu3405 $\rightarrow$ GIn) diminishes receptor-mediated uptake of LDL. Clinical chemistry, 45(7), 1026-1038.

Fouchier, S. W., Kastelein, J. J., \& Defesche, J. C. (2005). Update of the molecular basis of familial hypercholesterolemia in The Netherlands. Human mutation, 26(6), 550-556.

García-Álvarez, I., Castillo, S., Mozas, P., Tejedor, D., Reyes, G., Artieda, M., \& Civeira, F. (2003). Diferencias en la presentación clínica en sujetos con fenotipo de 
hipercolesterolemia familiar por defectos en el receptor LDL y por defectos de la apo B-100. Revista española de cardiología, 56(8), 769-774.

Garcia-Garcia, A. B., Ivorra, C., Martinez-Hervas, S., Blesa, S., Fuentes, M. J., Puig, O., \& Chaves, F. J. (2011). Reduced penetrance of autosomal dominant hypercholesterolemia in a high percentage of families: Importance of genetic testing in the entire family. Atherosclerosis, 218(2), 423-430.

García-Moll, X y Kaski, J.C. Cardiopatía isquémica: marcadores de inflamación y riesgo cardiovascular. Rev Esp Cardiol; 52: 990-1.003. 2001

Goldstein JL, Hobbs HH y Brown MS. The SREBP pathway: regulation of cholesterol metabolism by proteolysis of a membrane -bound transcription factor. 2;89(3):331-40. 2002

Harrison. Principios de Medicina Interna. En H. N. Ginsberg, Trastornos del metabolismo de las lipoproteínas. pág. 2434-2440. 2001

Juárez-Muñoz, I. E., Anaya-Florez, M. S., Mejía-Arangure, J. M., Games-Eternod, J., Sciandra-Rico, M., Núñez-Tinoco, F., \& Miranda-González, D. (2006). Niveles séricos de colesterol y lipoproteínas y frecuencia de hipercolesterolemia en un grupo de adolescentes de la Ciudad de México. Boletín médico del Hospital Infantil de México, 63(3), 162-168.

Kalina, Á., Császár, A., Czeizel, A. E., Romics, L., Szabóki, F., Szalai, C., \& Williams, R. R. (2001). Frequency of the R3500Q mutation of the apolipoprotein B-100 gene in 
a sample screened clinically for familial hypercholesterolemia in Hungary. Atherosclerosis, 154(1), 247-251.

Kuan-Rau Chiou, Min-Ji Charng. Common mutations of familial hypercholesterolemia patients in Taiwan: Characteristics and implications of migrations from southeast China. Gene 498; 100-106. 2012

Kumar, V. (2005). Patología estructural y funcional (Doctoral dissertation, University of Washington).

Liyanage, K. E., Burnett, J. R., Hooper, A. J., \& van Bockxmeer, F. M. (2011). Familial hypercholesterolemia: epidemiology, Neolithic origins and modern geographic distribution. Critical Reviews in Clinical Laboratory Sciences, 48(1), 1-18.

Lombardi, M. P., Redeker, E. J., Defesche, J. C., Kamerling, S. W., Trip, M. D., Mannens, M. M., \& Kastelein, J. J. (2000). Molecular genetic testing for familial hypercholesterolemia: spectrum of LDL receptor gene mutations in the Netherlands. Clinical genetics, 57(2), 116-124.

Lorenzo, Ó., Blanco-Colio, L. M., Martín-Ventura, J. L., Sánchez-Galán, E., AresCarrasco, S., Zubiri, I., \& Tuñón, J. (2009). Nuevos mediadores implicados en la génesis de la aterosclerosis. Clínica e investigación en arteriosclerosis, 21(1), 25-33.

Miserez, A. R., \& Muller, P. Y. (2000). Familial defective apolipoprotein B-100: a mutation emerged in the mesolithic ancestors of Celtic peoples?. Atherosclerosis, 148(2), 433-436. 
Ribas, L. (2008). Genes implicados en las formas monogénicas de la hipercolesterolemia familiar. Revista de Endocrinología y Nutrición, 16(1), 24-31.

Robles-Osorio, L., Ordoñez, M. L., Aguilar-Salinas, C. A., Aurón-Gómez, M., TusiéLuna, M. T., Gómez-Pérez, F. J., \& Rull-Rodrigo, J. A. (2003). Familial Hypercholesterolemia Due to Ligand-Defective Apolipoprotein B100.: First Case Report in a Mexican Family. Archives of medical research, 34(1), 70-75.

Shen, H., Damcott, C. M., Rampersaud, E., Pollin, T. I., Horenstein, R. B., McArdle, P. F., \& Mitchell, B. D. (2010). Familial defective apolipoprotein B-100 and increased low-density lipoprotein cholesterol and coronary artery calcification in the old order amish. Archives of internal medicine, 170(20), 1850-1855.

Sveger, T., \& Nordborg, K. (2004). Apolipoprotein B as a marker of familial hyperlipoproteinemia. Journal of atherosclerosis and thrombosis, 11(5), 286-292.

Vaca, G., Vàzquez, A., Magaña, M. T., Ramìrez, M. L., Dàvalos, I. P., Martìnez, E., \& Carrillo, G. (2011). Mutational analysis of the LDL receptor and $<\mathrm{i}>\mathrm{APOB}<\mathrm{i}>$ genes in Mexican individuals with autosomal dominant hypercholesterolemia. Atherosclerosis, 218(2), 391-396.

Voet, D., \& Voet, J. G. (2006). Bioquímica. Ed. Médica Panamericana. 


\section{Glosario}

ADN (ácido desoxirribonucleico): Molécula que contiene la información genética primaria en forma de una secuencia lineal de nucleótidos.

Alelo: Es cada una de las formas alternativas que puede tener un gen que se diferencian en su secuencia y que se puede manifestar en modificaciones concretas de la función de ese gen.

Alélica, frecuencia: Frecuencia de cierto alelo en un locus determinado en una población.

Apolipoproteína: Las apolipoproteínas (“apo" designa la proteína en su forma libre de lípidos) se combinan con los lípidos para formar diversas clases de partículas lipoproteicas, complejos esféricos con lípidos hidrofóbicos en el núcleo y cadenas laterales hidrofílicas de aminoácidos de la proteína en la superficie.

Apolipoproteína B100: Es una proteína y es el único componente proteico de la lipoproteína de baja densidad (LDL) que reconoce el receptor de LDL.

Aterosclerosis: Es un proceso inflamatorio crónico que afecta a las arterias de diferentes lechos vasculares y que se caracteriza por el engrosamiento de la capa íntima y media con pérdida de la elasticidad.

Citocinas: Proteínas sintetizadas por muchos tipos de células distintas que intervienen en las reacciones inflamatorias e inmunitarias. Las citocinas son los principales mediadores de la comunicación entre las células del sistema inmune.

Exón: Es la región del ADN que codifica para una porción específica. 
Hipercolesterolemia: Es la presencia de niveles elevados de colesterol en la sangre.

Hipercolesterolemia Familiar: Es un trastorno en el metabolismo de las lipoproteínas de baja densidad (LDL-c) se hereda de forma autosómica dominante, se caracteriza por altos niveles de LDL-colesterol en plasma, y los resultados son enfermedad cardíaca coronaria prematura.

Gen: Es una secuencia ordenada de nucleótidos en la molécula de ADN (o ARN, en el caso de algunos virus) que contiene la información necesaria para la síntesis de una macromolécula con función celular específica, habitualmente proteínas pero también ARNm, ARNr y ARNt.

Génica, frecuencia: Es la frecuencia o proporción de genotipos en una población.

Genotipificación: El proceso de determinación del genotipo o contenido genómico, en forma de ADN, específico de un organismo biológico, mediante un procedimiento de laboratorio.

Lipoproteína: Son complejos macromoleculares de proteínas transportadoras específicas, denominadas apolipoproteínas, con diversas combinaciones de fosfolípidos, colesterol, ésteres de colesterol y triacilgliceroles.

Marcador genético: Alelo utilizado para reconocer un genotipo determinado

Polimorfismo: Existencia de dos o más formas alternativas de un gen particular que se encuentra en la población en una frecuencia significativa mayor del 1\%. 
Polimorfismo de Nucleótido Simple (SNP): Es una variación en la secuencia de ADN que afecta a una sola base (adenina $(A)$, timina $(T)$, citosina $(C)$ o guanina $(G)$ ) de una secuencia del genoma. Sin embargo, algunos autores consideran que cambios de unos pocos nucleótidos, como también pequeñas inserciones y deleciones (indels) pueden ser consideradas como SNP. 


\section{Anexo I.}

\section{l.1. Técnica para la extracción y cuantificación de ADN.}

Obtención de ADN a partir de sangre periférica:

1.- Se centrifuga la muestra de sangre a $7000 \mathrm{rpm} \times 20 \mathrm{~min}$.

2.- Se retira el plasma y se coloca en tubos eppendorf y se obtienen blancos (leucocitos) y se transfieren en un tubo falcón de $15 \mathrm{ml}$, se adiciona a este

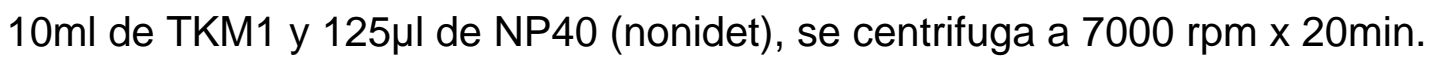

3.- Se retira el sobrenadante y se lava con $10 \mathrm{ml}$ de TKM1 y $125 \mu \mathrm{l}$ de nonidet, se centrifuga a 7000rpm x $20 \mathrm{~min}$.

4.- Se retira el sobrenadante y se lava con $10 \mathrm{ml}$ de TKM1 se lleva al vortex hasta romper los glóbulos rojos (eritrocitos), se centrifuga a 7000rpm x 20min.

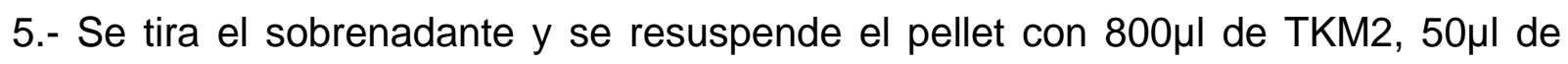
SDS al $10 \%, 30 \mu \mathrm{l}$ de proteinasa K y $10 \mu \mathrm{l}$ de RNAsa.

6.- Se deja incubando por 24 horas a $55^{\circ} \mathrm{C}$.

7.-Transcurrido el tiempo de incubación se adiciona $300 \mu \mathrm{l}$ de $\mathrm{NaCl} 6 \mathrm{M}$, en el tubo, mezclar bien. Centrifugar a 14000 rpm por 5 min.

8.- El sobrenadante se transfiere a un falcón de $15 \mathrm{ml}$ y se adiciona dos volúmenes de etanol frío al 100\% (absoluto), e invertir varias veces hasta que precipite el ADN. 
9.- La muestra se centrifuga a $7000 \mathrm{rpm} \times 20 \mathrm{~min}$, el sobrenadante se desecha y la pastilla se resuspende con agitación en $1 \mathrm{ml}$ de etanol al $70 \%$ frío.

10.- El ADN se centrifuga a 7000rpm $\times 10 \mathrm{~min}$, el sobrenadante se decanta y la muestra se seca a temperatura ambiente por $20 \mathrm{~min}$. Después se resuspende en $500 \mu / / 300 \mu l$ de TE y se deja incubando 24 horas.

11.- Se cuantifica el ADN obtenido.

\section{I.2. Cuantificación de ADN.}

Para la cuantificación del ADN se emplea el análisis de la absorción UV, ya que los nucleótidos poseen máximos de absorción alrededor de 260nm/280nm. Si la relación es mayor a 1,6 puede estimarse que la muestra es lo bastante pura, sin contaminación significativa de proteínas o solventes orgánicos. La media para las nuestras muestras es de 1.9, lo cual indica que son bastante puras y su contenido es prioritariamente ADN.

El procedimiento es el siguiente:

1.-Se toman $2 \mu \mathrm{l}$ de la muestra de ADN obtenido y se agregan $98 \mu \mathrm{l}$ de agua desionizada. Se mezcla y se transfiere a una celda.

2.- Se mide en el espectrofotómetro la densidad óptica (OD) a 260nm.

3.-Para analizar la pureza de la muestra, se toma una segunda lectura a $280 \mathrm{~nm}$. Determinar la relación de OD a 260nm / OD a 280nm. Si ésta es aproximadamente 2 (de 1,6 a 2) la absorción es mayoritariamente debida a ácidos nucleicos. 


\section{Anexo II}

\section{II.1 Reacción en cadena de la polimerasa (PCR).}

Es una técnica de biología molecular desarrollada en 1987 por Kary Mullis, cuyo objetivo es obtener un gran número de copias de un fragmento de ADN particular, partiendo de un mínimo; en teoría basta partir de una única copia de ese fragmento original, o molde.

PCR en tiempo real: Es una variante de la reacción en cadena de la polimerasa (PCR) utilizada para amplificar y simultáneamente cuantificar de forma absoluta el producto de la amplificación de ácido desoxirribonucleico (ADN). Para ello emplea, del mismo modo que la PCR convencional, un molde de ADN, al menos un par de cebadores específicos, dNTPs, un tampón de reacción adecuado, y una ADN polimerasa termoestable; a dicha mezcla se le adiciona una sustancia marcada con un fluoróforo que, en un termociclador que albergue sensores para medir fluorescencia tras excitar el fluoróforo a la longitud de onda apropiada, permita medir la tasa de generación de uno o más productos específicos. Dicha medición, se realiza luego de cada ciclo de amplificación y es por esto que también se le denomina PCR en tiempo real (es decir, PCR inmediata, simultánea). En muchos casos el molde que se emplea para la PCR cuantitativa no es desde el principio ADN, sino que puede ser ADN complementario (ADNc), de hebra simple, obtenido por retrotranscripción de ácido ribonucleico (ARN); en este caso, la técnica es una RT-PCR cuantitativa o en tiempo real, o RT-Q-PCR. 
Sondas TaqMan: La PCR en tiempo real puede realizarse marcando fluorescentemente oligonucleótidos que detectan específicamente la aparición del producto deseado. El fundamento de esta técnica se basa en el empleo del FRET o transmisión de energía de resonancia, que es un mecanismo de transferencia de energía entre cromóforos. Las sondas TaqMan permiten medir la producción de productos de PCR mediante un sistema de sondas marcadas mediante dos fluorocromos. Su utilidad radica en que poseen un fluoróforo en su extremo 3' y una molécula en el 5' que bloquea su emisión de fluorescencia (denominada en inglés «quencher»); esta sonda marcada híbrida específicamente en la parte central del producto de PCR a obtener. De este modo, cuando se efectúa la PCR (con la sonda más el par de cebadores específicos), la sonda híbrida en el amplicón, pero, debido a la cercanía del fluoróforo al quencher, no se emite fluorescencia; cuando la polimerasa se topa con la sonda la hidroliza mediante su actividad exonucleasa 5'-3', lo cual provoca la separación del quencher del fluorocromo y, por tanto, la emisión de fluorescencia. Fluorescencia que está relacionada con la cantidad de amplicón producido. 


\section{Mecanismo de las sondas TaqMan}



Figura 13. Las sondas TaqMan poseen una secuencia de 10-12 nucleótidos que es complementaria con la secuencia de ADN a localizar el SNP, como se muestra en la figura si se emite fluorescencia para VIC es homocigoto para el alelo 1 y si el FAM para el alelo 2 y si se emite fluorescencia para ambos es heterocigoto. 


\section{Anexo III}

\section{Carta de consentimiento informado por escrito INP.}

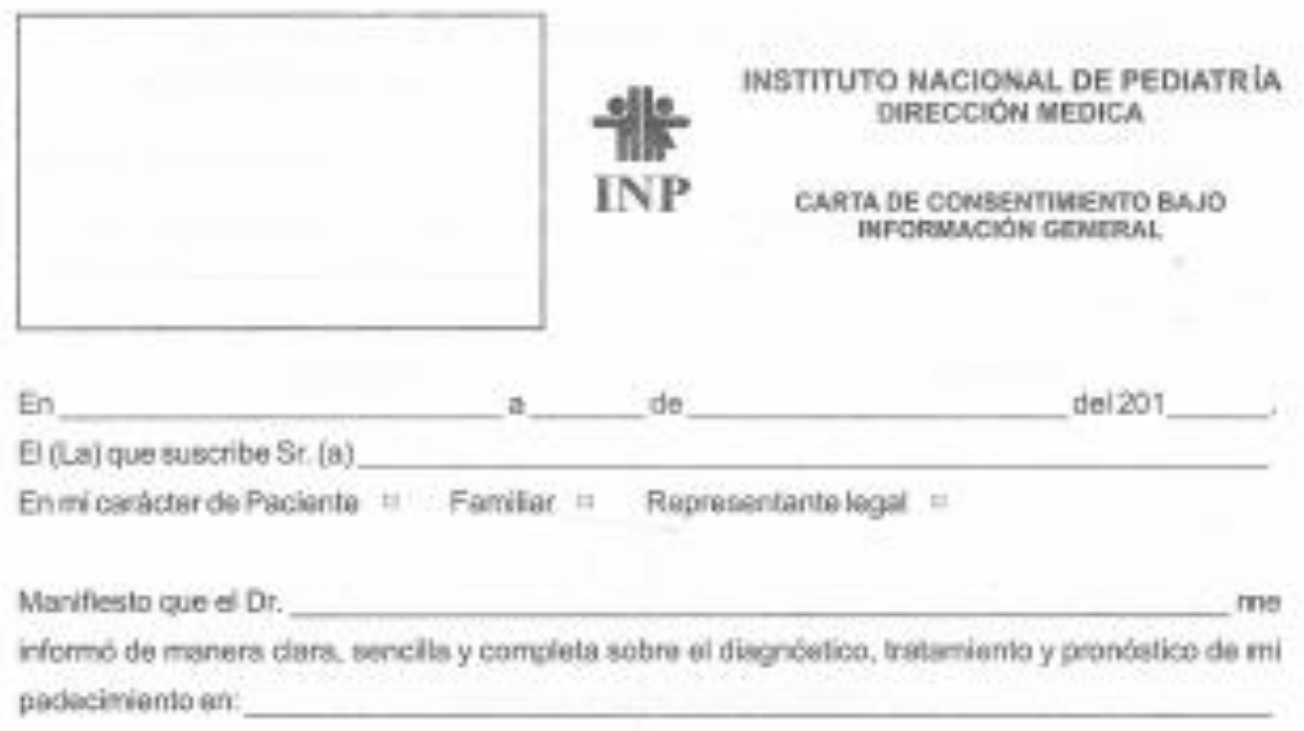

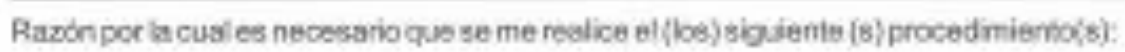

Losberseficios eaperadis atn:

Losposides neegos ocamplicaciones, poeden Ber:

A fimar aste consantmiento sin ambsygo, permite a los medicos dsponer de sus registros para

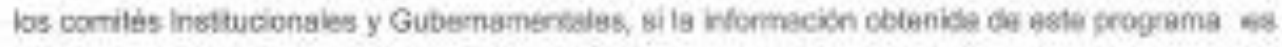
pubicsida, neseid idersilicade pornombre

El(L) que suscribe. en plengusede mis

Farfutades, marifisato astar cabidemente entarado $\{a\}$ dod contenido ded presente documento, para la cual firmo para doratancia y efoctos logstes a que haya lugar. 


\section{FIRMA DE CONSENTIMIENTO DEL PACIENTE O REPRESENTANTE LEGAL.}

Nombre:

Parantsco:

Fima: Damictio:

Identifoacibr:

TESTIGO 1

TESTIGO 2

Nombre: Nombre:

Fimia: Firms:

Domicilia: Domicile:

Identhicación: Identificsciom:

\section{DECLARACION DEL MÉDICO}

Ho explicado al paciente o persons autorizada para otorgar el presemle corsentimiento, la naturalaza de la (a) condeicon (as) que preacente an la actualidad. Adernis le he informado, sobre los métodos de disgóstoo y tratamienbo, exepicando con un lenguaje comin los benefncios esperadca y los posibies riesgos o complicaciones que pudieran estar asceladas a este procedimionbo (s) El (ja)

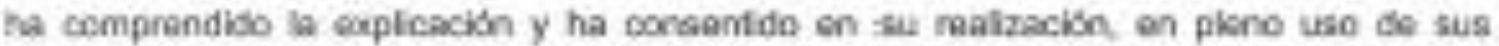
toculades.

Deportsmento o Servicio:

Nombre del Medica:

Firme: Fecha:

Rocibi copia de Carla de Consentimiento Indormsdo.

Nombre:

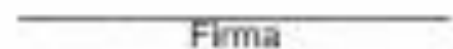

Fima

Este tomalo debeseranexsdo al expediente dinico. 